\title{
A LabVIEW-based electrical bioimpedance spectroscopic data interpreter (LEBISDI) for biological tissue impedance analysis and equivalent circuit modelling
}

\author{
Tushar Kanti Bera ${ }^{1}$, Nagaraju Jampana ${ }^{2}$ and Gilles Lubineau ${ }^{1}$ \\ 1. King Abdullah University of Science and Technology (KAUST), COHMAS Laboratory, Thuwal 23955-6900, Saudi Arabia \\ 2. Department of Instrumentation and Applied Physics, Indian Institute of Science, Bangalore-560012, INDIA \\ 3. E-mail any correspondence to: tushar.bera@kaust.edu.sa, gilles.lubineau@kaust.edu.sa
}

\begin{abstract}
Under an alternating electrical signal, biological tissues produce a complex electrical bioimpedance that is a function of tissue composition and applied signal frequencies. By studying the bioimpedance spectra of biological tissues over a wide range of frequencies, we can noninvasively probe the physiological properties of these tissues to detect possible pathological conditions. Electrical impedance spectroscopy (EIS) can provide the spectra that are needed to calculate impedance parameters within a wide range of frequencies. Before impedance parameters can be calculated and tissue information extracted, impedance spectra should be processed and analyzed by a dedicated software program. National Instruments (NI) Inc. offers LabVIEW, a fast, portable, robust, user-friendly platform for designing dataanalyzing software. We developed a LabVIEW-based electrical bioimpedance spectroscopic data interpreter (LEBISDI) to analyze the electrical impedance spectra for tissue characterization in medical, biomedical and biological applications. Here, we test, calibrate and evaluate the performance of LEBISDI on the impedance data obtained from simulation studies as well as the practical EIS experimentations conducted on electronic circuit element combinations and the biological tissue samples. We analyze the Nyquist plots obtained from the EIS measurements and compare the equivalent circuit parameters calculated by LEBISDI with the corresponding original circuit parameters to assess the accuracy of the program developed. Calibration studies show that LEBISDI not only interpreted the simulated and circuitelement data accurately, but also successfully interpreted tissues impedance data and estimated the capacitive and resistive components produced by the compositions biological cells. Finally, LEBISDI efficiently calculated and analyzed variation in bioimpedance parameters of different tissue compositions, health and temperatures. LEBISDI can also be used for human tissue impedance analysis for electrical impedance-based tissue characterization, health analysis and disease diagnosis.
\end{abstract}

Keywords: Electrical Bioimpedance, Electrical Impedance Spectroscopy (EIS), LabVIEW-Based Electrical Bioimpedance Spectroscopic Data Interpreter (LEBISDI), Curve Fitting, Nyquist Plots, Equivalent Circuit Modelling.

\section{Introduction}

Biological tissues are made of complex three-dimensional arrangements of cells embedded in an extracellular matrix called extracellular fluid (ECF). Cells contain intracellular fluid (ICF), called protoplasm, which in an animal cell is enclosed by the cell membrane (CM) and in a plant cell is surrounded by both a $\mathrm{CM}$ and a cell wall (CW). When subjected to an alternating current signal, animal and plant cells differ in their electrical responses, indicating that both tissue composition and the frequency of an applied AC signal affect their electrical responses [1-4]. The electrical behavior of the tissues is usually quantified by its complex bioelectrical impedance [1-4], which is the physical quantity that we reconstruct from the experimental measurements. Because bioelectrical impedance depends on the physiological and physiochemical status of the probed tissue and because it also varies from subject to subject and with changes in the health status of the tissue [5-6], such as inflammation, infection and disease, studying how a tissue responds to frequency can provide valuable information about its anatomy and physiology. Many researchers [7-23] have investigated electrical bioimpedance as an effective, noninvasive method to probe the pathological status of biological tissues.

For example, bioelectrical impedance analysis (BIA) [7-10], electrical impedance spectroscopy (EIS) [11-21], impedance plethysmography (IPG) [22-23] and impedance cardiography (ICG) [24-26] reveal the impedance response of biological tissues at one, two or more specified frequencies (f). EIS has been proven as an effective technique for noninvasive tissue characterization in medical, biomedical and biological applications [27-36]. Because EIS is a more generalized method that provides impedance variations over a wide range of frequencies, it can be used on its own to provide information that explains other bioelectrical phenomena like dielectric polarization [37-41], dielectric relaxation [37-41] and dielectric dispersion [37-41].

Impedance spectra obtained from EIS can be used to study the overall anatomy and physiology of organic tissues. Impedance parameter plots, such as Nyquist plots (Imaginary part of $Z$ versus Real part of $Z$ ), impedance $(Z)$ versus frequency (f) plots (Bode plots), conductivity $(\sigma)$ 
versus frequency (f) plots and permittivity ( $\varepsilon$ ) versus frequency (f) plots, are popular tools for visualizing different aspects of bioelectrical impedance. In particular, Nyquist plots distinguish real from imaginary parts of bioimpedance and serve as a guide to define equivalent electrical circuit parameters. Because equivalent electrical circuit models or equivalent circuit models (ECM) $[6,13]$ are very useful for understanding the anatomical, physiological and compositional aspects of biological tissues, an accurate analysis of data plots is required for effective assessment of a tissue's properties.

Impedance analyzers are used either to measure the electrical impedance of materials at a single frequency or to study impedance variation over a wide range of frequencies. Impedance analyzers are typically developed with selected current frequency limits and other fixed specifications. Occasionally, changes to measurement parameters are required for a specific application, making the individual development of impedance measurement systems [42-50] advantageous and essential. Impedance analyzers or the impedance measurement hardware developed as low-cost [42, 46] and application-specific instrumentation measure the impedance data, but it requires some complementary dedicated software to process and analyze the impedance response of materials. More specifically, this software is required to calculate impedance parameters and extract tissue information by identifying the equivalent electrical circuit of the material being tested. Modern electronics technology offers a number of fast, portable, robust, user-friendly platforms for analog or digital data acquisition and signal processing that can be suitably utilized for developing a standalone impedance measurement workbench. When a standalone impedance measurement workbench is developed to collect the impedance data, it is found essentially required to be complemented by any software program or virtual instrumentation such as LabVIEW (Laboratory Virtual Instrument Engineering Workbench) [51] for impedance data analyzing.

Here, we developed a LabVIEW-based electrical bioimpedance spectroscopic data interpreter (LEBISDI) for tissue impedance analysis in medical, biomedical and biological applications by extracting the equivalent circuit parameters of biological tissues using their Nyquist plots. We tested and calibrated the LEBISDI software with both the computer-simulated impedance data and experimental impedance data collected from a number of electronic circuit combinations developed by high-precision resistors, capacitors and inductors using a standard impedance analyzer using low amplitude, sinusoidal current signal. We then used LEBISDI to interpret impedance data collected from fruits and vegetables under different physiological conditions. We conducted EIS studies on these tissues using a standard impedance analyzer. We used LEBISDI to analyze their Nyquist plots to calculate and correlate the electrical impedance parameters of the compositions, structures and conditions of the tissues.

\section{Materials and methods}

\subsection{Bioelectrical Impedance (Zb) and Electrical Impedance Spectroscopy (EIS)}

Biological tissues comprise cells and an extracellular matrix. Both have their own electrical behavior and collectively produce a complex, frequency-dependent bioelectrical impedance, $Z_{b}(f)$ [39]. The impedance $Z_{b}(f)$ and its frequency-dependent phase angle, $\theta_{\mathrm{b}}(\mathrm{f})$ are given by:

$$
\begin{aligned}
& Z_{b}(f)=R_{b}(f)-j X_{b}(f) \\
& \theta_{b}(f)=-\tan ^{-1}\left(\frac{X_{b}}{R_{b}}\right)
\end{aligned}
$$

where $R_{b}(f)$ and $X_{b}(f)$ are the real and imaginary parts of $Z_{b}$ respectively and $j$ is the complex number $\sqrt{ }(-1)$. Both $R_{b}(f)$ and $X_{b}(f)$ depend on the signal frequency and tissue composition such that

$$
\begin{aligned}
& \mathrm{R}_{\mathrm{b}}(\mathrm{f})=|\mathrm{Z}(\mathrm{f})| \cos \left(\theta_{\mathrm{b}}(\mathrm{f})\right) \\
& \mathrm{X}_{\mathrm{b}}(\mathrm{f})=-|\mathrm{Z}(\mathrm{f})| \sin \left(\theta_{\mathrm{b}}(\mathrm{f})\right)
\end{aligned}
$$

EIS measures $Z_{b}$ and its phase angle $\left(\theta_{b}\right)$ of a test subject by injecting a constant amplitude, alternating current (AC) signal (I(f)) at different frequency points, $f_{i}\left(f_{i}: f_{1}, f_{2}, f_{3}, \ldots\right.$ $\left.\mathrm{f}_{\mathrm{n}}\right)$, and by measuring the boundary potentials $\left(\mathrm{V}\left(\mathrm{f}_{\mathrm{i}}\right)\right)$ through using a linear array of the surface electrodes attached to the subject (Figure 1) though other configurations could also be used such as placing the electrodes like the corners of a rectangle [52].

The impedance of a material is generally measured either by the two-electrode method $[8,20]$ or four-electrode method $[8,20,50]$. In the two-electrode method, as the name indicates, two surface electrodes are used for current injection and voltage measurement. As shown in Figure 1a, in the two-electrode method the current injection and voltage measurement are conducted through the same electrode pair $[8,20]$. Thus, the measurement data contains the effect of contact impedance $(\mathrm{Zc})$. To avoid the contact impedance problem, the impedance measurement is conducted with the four-electrode method as shown in Figure $1 \mathrm{~b}$ and Figure 1c. Thus, the four-probe method (Figure 1b) of the impedance measurement process is usually preferred to make the measurement insensitive to the impedance of the electrodes and wiring systems. In the four-probe method, a frequency-dependent constant amplitude sinusoidal current (I(f)) is injected through the outermost two electrodes, called the current or driving electrodes (red electrodes in Figure $1 \mathrm{~b}$ and 1c), and the frequency-dependent $\mathrm{AC}$ voltage $(\mathrm{V}(\mathrm{f}))$ is measured [13] 
across the two inner electrodes, called the voltage or sensing electrodes (blue electrodes in Figure $1 \mathrm{~b}$ and $1 \mathrm{c}$ ). From Ohm's law of AC theory, $\mathrm{Z}_{\mathrm{b}}(\mathrm{f})$ is the transfer function of the test subject, which is calculated from the voltagecurrent data by dividing V(f) by I(f):

$$
Z_{b}(f)=\frac{V(f)}{I(f)}
$$

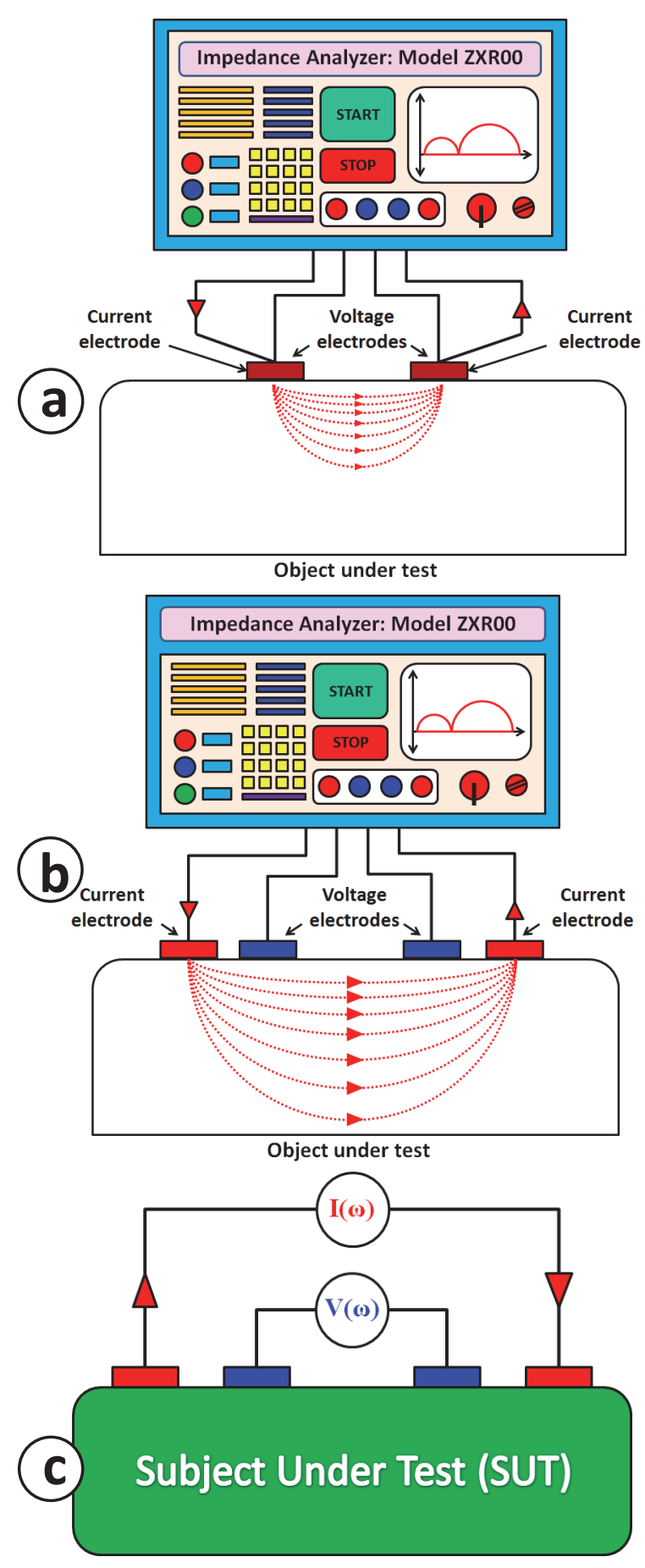

Fig.1: Electrical impedance spectroscopy (EIS) studies using the two-probe and four-probe technique. (a) EIS measurements with an impedance analyzer using two-electrode method. (b) EIS measurements with an impedance analyzer using four-electrode method. (c) Current injection and voltage measurement using the four-probe method of the impedance measurement system.
In bioimpedance spectroscopy, variations in bioelectrical impedance over frequencies are represented as impedance curves and are analyzed to characterize the tissue. As an example, the real part $\left(\mathrm{R}_{\mathrm{b}}\right)$ and imaginary part $\left(\mathrm{X}_{\mathrm{b}}\right)$ of $\mathrm{Z}_{\mathrm{b}}$ at each frequency point $\left(\mathrm{f}_{\mathrm{i}}: \mathrm{i}=1,2,3, \ldots, \mathrm{n}\right)$ are calculated and plotted (along the $\mathrm{x}$-axis and $\mathrm{y}$-axis, respectively) to obtain the Nyquist Plot $[6,13]$ or the $R_{b}-X_{b}$ spectrum.

\subsection{Equivalent Electrical Circuit Modeling}

The lumped electrical impedance value of any material (non-biological and biological) measured at a particular frequency can be represented by the impedance obtained from its equivalent electrical circuit model, which can be a combination of circuit elements such as resistance (R), capacitance (C) and inductance (L). If we define the complex electrical impedance (Z) for any particular material (either non-biological or biological), then

$$
Z(f)=\operatorname{Re}(Z(f))-j \operatorname{Im}(Z(f))=R_{z}(f)-j X_{z}(f),
$$

where $\operatorname{Re}(\mathrm{Z}(\mathrm{f}))=\mathrm{R}_{\mathrm{z}}(\mathrm{f})$ represents the magnitude of the real part of complex $Z$ and $\operatorname{Im}(Z(f))=X_{Z}(f)$ represents the magnitude of the imaginary part of the $Z(f)$.

If the material contains both capacitive and inductive elements, then the reactive component $\left(\mathrm{X}_{\mathrm{z}}\right)$ will have two components called the frequency-dependent inductive reactance component, $\mathrm{X}_{\mathrm{L}}(\mathrm{f})$, and the frequency-dependent capacitive reactance component, $\mathrm{X}_{\mathrm{C}}(\mathrm{f})$. Thus, we have:

$$
Z(f)=R_{z}(f)+j\left(X_{L}(f)-X_{C}(f)\right)
$$

Similarly, in EIS studies on biological material, the measured $Z_{b}$ of the test subject can also be represented by an equivalent impedance $\left(\mathrm{Z}_{\mathrm{eq}}\right)$. This $\mathrm{Z}_{\mathrm{eq}}$ can be obtained from a combination of some electrical circuit elements (e.g., R and/or C) because the magnetic effect of the biological tissues at low frequency is negligible [53]. Moreover, the equivalent circuit model of biological tissues may also contain some special circuit elements, such as a constant phase element (CPE) [13] or Warburg impedance (W) [13] and/or some complex bioelectrical phenomena occurring inside the biological tissues due to the physiological changes that take place when they are subjected to AC excitation. Warburg impedance represents the electrode's interfaces and the CPE is often interpreted as a parameter describing the distribution of relaxation times [54] in the system, e.g. due to a distribution of cell sizes.

The Nyquist plot is the plot of imaginary part of impedance $\left(\mathrm{X}_{\mathrm{z}}\right)$ versus the real part of impedance $\left(\mathrm{R}_{\mathrm{z}}\right)$. The approximate equivalent circuit model of the material can be found from the $\mathrm{X}_{\mathrm{z}}-\mathrm{R}_{\mathrm{z}}$ curve (Nyquist plots) which is generally obtained from the EIS data. Electrical impedance spectroscopic analysis followed by the equivalent circuit modeling establishes the relationship between the tissue 
property and its impedance response. As for example, the Nyquist plots of some basic circuit models have been discussed in the Figure 2.
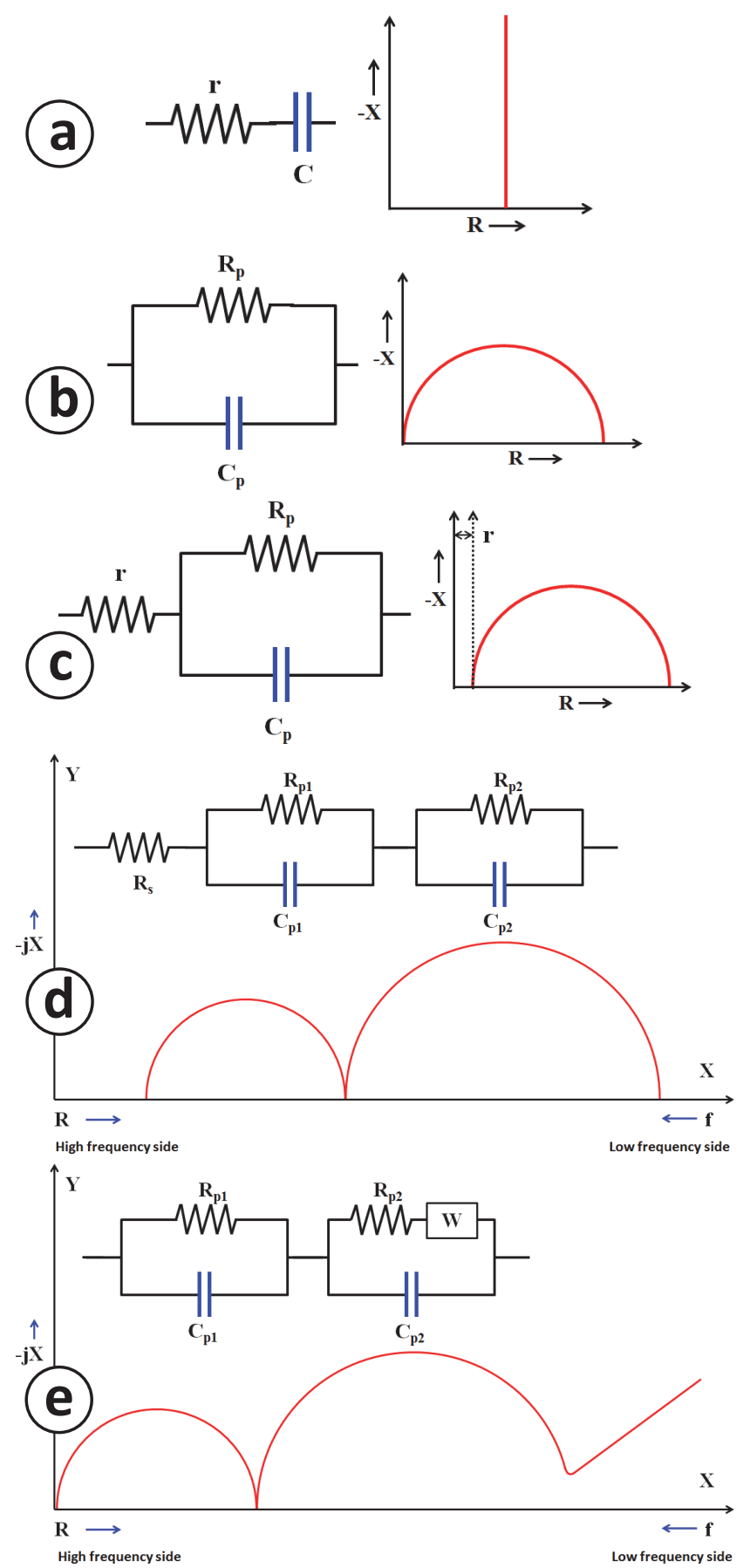

Fig.2: Nyquist plots for different circuit combinations. (a) Nyquist plots for a circuit combination containing a resistor $\mathrm{r}$ and a capacitor $\mathrm{C}$ in series, (b) Nyquist plots for a circuit combination containing a resistor $R_{p}$ and a capacitor $C_{p}$ in parallel $\left(R_{p} \| C_{p}\right)$, (c) Nyquist plots for a circuit combination containing two sub-circuit blocks with a series resistance of $R_{s}$ and the parallel combination of $R_{p}$ and a capacitor $C_{p}\left(R_{p} \| C_{p}\right)(d)$ Nyquist plots for a circuit combination containing three subcircuit blocks with a series resistance of $\mathrm{R}_{\mathrm{s}},\left(\mathrm{R}_{\mathrm{p} 1} \| \mathrm{C}_{\mathrm{p} 1}\right)$ and $\left(\mathrm{R}_{\mathrm{p} 2} \|\right.$ $\mathrm{C}_{\mathrm{p} 2}$ ). (e) Nyquist plots for a circuit combination containing two sub-circuit blocks, $\left(\mathrm{R}_{\mathrm{p} 1} \| \mathrm{C}_{\mathrm{p} 1}\right)$ and $\left(\left(\mathrm{R}_{\mathrm{p} 2}+\right.\right.$ Warburg impedance $(\mathrm{W})) \| \mathrm{C}_{\mathrm{p} 2}$ ), connected in series.
Figure 2a shows a r-C series circuit and its impedance spectra (Nyquist plot). Figure 2b shows an electrical circuit model containing $\mathrm{R}_{\mathrm{p}}$ and $\mathrm{C}_{\mathrm{p}}$ connected in parallel and its Nyquist plot. As shown in Figure 2b, the Nyquist plot contains a semi-circular arc that represent the two parallel circuit blocks, $\left(\mathrm{R}_{\mathrm{p}} \| \mathrm{C}_{\mathrm{p}}\right)$.

If a model contains a series resistance (r) along with the parallel branch $\left(R_{p} \| C_{p}\right)$ as shown in Figure $2 c$, the impedance spectra will be shifted toward positive real axis and the amount of the shift will indicate the magnitude of the resistance r. Figure $2 \mathrm{~d}$ shows an equivalent electrical circuit model of an object containing several $\mathrm{R}$ and $\mathrm{C}$ components and its impedance spectra. This model contains three sub-circuit blocks or sub-circuit parts connected in series: $R_{s},\left(R_{p 1} \| C_{p 1}\right)$ and $\left(R_{p 2} \| C_{p 2}\right)$. As shown in Figure $2 d$, the Nyquist plot contains two semi-circular arcs that represent the two parallel circuit blocks, $\left(\mathrm{R}_{\mathrm{p} 1} \| \mathrm{C}_{\mathrm{p} 1}\right)$ and $\left(\mathrm{R}_{\mathrm{p} 2} \| \mathrm{C}_{\mathrm{p} 2}\right)$. The high-frequency part of the spectra (left side of the graph) cuts the $\mathrm{x}$-axis at a particular distance away from the $y$-axis, and this distance represents the series resistance $\left(R_{s}\right)$. Similarly, Figure 2e shows the Nyquist plot of a different electrical circuit model, which contains two parts connected in series, $\left(\mathrm{R}_{\mathrm{p} 1} \| \mathrm{C}_{\mathrm{p} 1}\right)$ and $\left(\left(\mathrm{R}_{\mathrm{p} 2}+\mathrm{W}\right) \| \mathrm{C}_{\mathrm{p} 2}\right)$. Its impedance spectra contain two semi-circular arcs for two parallel circuit blocks, $\left(\mathrm{R}_{\mathrm{p} 1} \| \mathrm{C}_{\mathrm{p} 1}\right)$ and $\left(\left(\mathrm{R}_{\mathrm{p} 2}+\mathrm{W}\right) \| \mathrm{C}_{\mathrm{p} 2}\right)$. The linear part of the spectra on the low-frequency side (right side of the graph) indicates Warburg impedance (W) [5559], resulting from the diffusion effect [58-61] on electrodes at low frequencies.

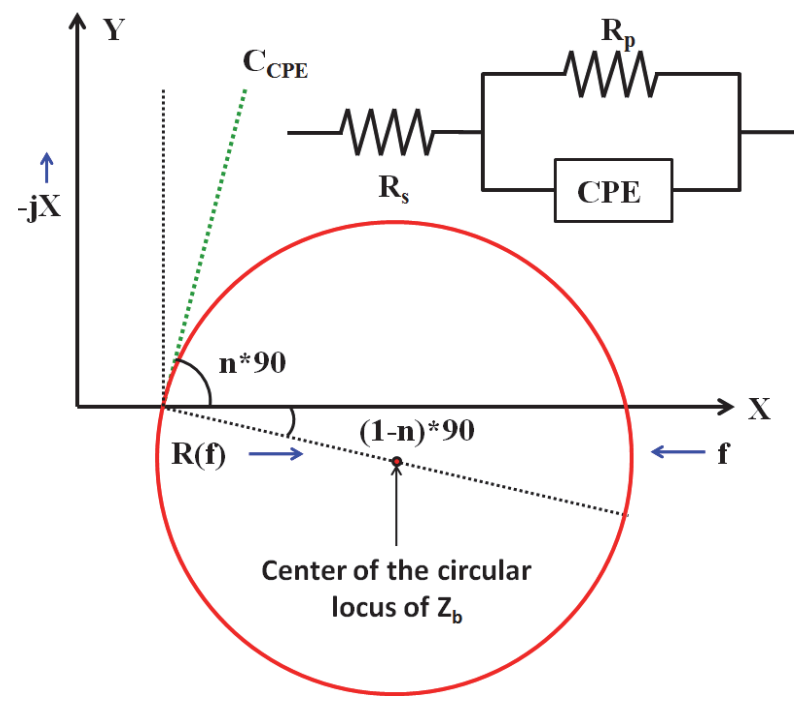

Fig.3: Nyquist plots of circuit combinations containing two subcircuit blocks: one with series resistance, $R_{s}$, and another containing a CPE in parallel with resistance $R_{p}\left(R_{p} \| C P E\right)$.

In some cases, the Nyquist plots are semi-circular arcs with their centers some distance below the $\mathrm{x}$-axis. These depressed semi-circular Nyquist plots are complex to analyze because of the involvement of the CPE circuit. Figure 3 presents a depressed semi-circular Nyquist plot, where the equivalent circuit contains the CPE in parallel 
with R. The high-frequency side of the semi-circular arc cuts the $\mathrm{x}$-axis at a particular distance away from the $\mathrm{y}$-axis and the distance represents $\mathrm{R}_{\mathrm{s}}$.

By definition, the impedance of the $\mathrm{CPE}\left(\mathrm{Z}_{\mathrm{CPE}}\right)$ shown in Figure 3 is represented as:

$$
\mathrm{Z}_{\mathrm{CPE}}=\mathrm{Q}\left(\frac{1}{\mathrm{j} . \omega}\right)^{\mathrm{n}}=\frac{1}{\mathrm{Y}_{0}}(\mathrm{j} \cdot 2 \pi f)^{-\mathrm{n}}
$$

where $Q$ is the magnitude of $Z_{C P E}$ and $Y_{0}=1 / Q, j=\sqrt{ }-1$ and $0<\mathrm{n}<1$.

Note that the phase angle $(\phi)$ of $Z_{\mathrm{CPE}}$ is frequency independent. It thus remains constant throughout the frequency range of EIS. The $\phi$ of $Z_{\mathrm{CPE}}$ is given by:

$$
\phi=-(90 * n) \text {. }
$$

For an object with CPE, when $\mathrm{n}$ is less than 1 , the CPE resembles a capacitor, but not a pure capacitor because $\phi$ is less than $90^{\circ}$. As the value of $n$ increases, CPE gradually becomes more capacitive. At $\mathrm{n}=1, \mathrm{Y}_{0}$ becomes a pure capacitor (CCPE) for which

$$
Z_{C P E}=X_{C}=C_{C P E}(j \omega)^{-1}=\frac{1}{j \omega C_{C P E}}=-\frac{j}{\omega C_{C P E}}=-\frac{j}{2 \pi f C_{C P E}}
$$

Nyquist plots of the circuits with a CPE are strongly influenced by circuit element combinations. When a material contains CPE and a resistive element, $R_{p}$, parallel to each other, the Nyquist plot (R-X plot) of the material will be a semi-circular path depressed by an angle of (1n) $* 90^{\circ}$, as shown in Figure 3. But the R-X spectrum of a $\mathrm{CPE}$ alone is a straight line, generating an angle of $\left(\mathrm{n}^{\left.* 90^{\circ}\right)}\right.$ with a positive $\mathrm{x}$-axis (green dotted line in Figure 3).

\subsection{Equivalent Circuit Modeling of Biological Tissues}

Biological cells and tissues can be modeled by analysis of their impedance responses obtained from EIS studies conducted within a suitable frequency range. The impedance response of a biological cell is strongly influenced by cell composition [62-63]. The individual electrical properties of each cell's composition are thus represented by their equivalent electric circuit elements, which can be used to develop an equivalent circuit model of a single cell $[6,13,64-70]$, as described in the following sections.

Animal cells can be modeled with an equivalent circuit concept as shown in Figure 4. The resistive path created by the ICF in biological cells to an electric signal (Figure 4a) is represented as a resistive element called ICF resistance $\left(\mathrm{R}_{\mathrm{ICF}}\right)$. Alternatively, the capacitance [74] offered by the protein-lipid-protein structure [62-63] of the cell membrane is modeled as cell membrane capacitance $\left(\mathrm{C}_{\mathrm{CM}}\right)$ [5-6] (Figure 4a).
The equivalent impedance of the cell membrane and the protoplasm (which comprises cytoplasm and cell organelles) [71-72] is called $\mathrm{Z}_{\mathrm{PPCM}}$ (Figure $4 \mathrm{~b}$ ). Because the ECF is made up of conducting solution, it also creates a resistive path $[6,13,65]$ (Figure $4 a$ ) that exerts an electrical resistance called ECF resistance $\left(\mathrm{R}_{\mathrm{ECF}}\right)$. When cells are suspended in or by ECF, $\mathrm{R}_{\mathrm{ECF}}$ becomes a resistive element connected as a parallel branch to the $Z_{\text {PPCM}}$. Therefore, an animal cell suspended in ECFs can be modeled as an equivalent electrical circuit [66-70] called the equivalent electrical impedance of an animal cell $\left(Z_{\mathrm{AC}}\right)$, as shown in Figure 4b.

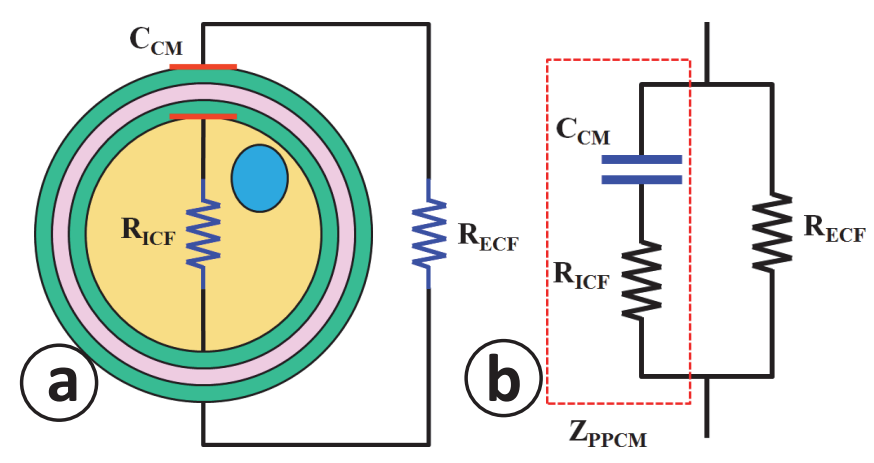

Fig.4: Equivalent electrical circuit modeling of animal cells. (a) An isolated animal cell and the electrical equivalence of the intracellular fluids (ICF), extracellular fluids (ECF) and the cell membrane (CM). (b) An equivalent electrical circuit model of an isolated animal cell surrounded by ECF.

Plant cells (Figure 5a) have cell walls made up of lowconducting materials, thus creating an additional resistive path that produces an electrical resistance called cell wall resistance $\left(R_{C W}\right)$. Thus, as the envelope surrounding the cell membrane, $\mathrm{R}_{\mathrm{CW}}$ is modeled as a resistance connected in parallel with $\mathrm{Z}_{\mathrm{PPCM}}$ (Figure $5 \mathrm{~b}$ ) of the plant cell. Moreover, similar to the animal cell, ECFs in plant cells also produce resistive paths (Figure 5b). They are thus represented as $\mathrm{R}_{\mathrm{ECF}}$ connected in parallel to the $Z_{\mathrm{PPCMCW}}$, which is the parallel combination of $Z_{\mathrm{PPCM}}$ and $\mathrm{R}_{\mathrm{CW}}$ (i.e., $Z_{\mathrm{PPCM}} \| \mathrm{R}_{\mathrm{CW}}$ ). Thus, as plant cells contain ECFs, a cell wall, a cell membrane and ICFs, they can be modeled as an equivalent electrical circuit called the equivalent electrical impedance of a plant cell $\left(\mathrm{Z}_{\mathrm{PC}}\right)$, as shown in Figure $5 \mathrm{~b}$.

If the plant cell contains a large vacuole, the model can be modified by incorporating the impedance properties exerted by the composition of the vacuole. The vacuole of a plant cell is a cell-like structure made up of vacuole sap surrounded by a vacuole membrane, which is called a tonoplast [73-74]. Thus, vacuole impedance can be modeled as a separate cell-like structure or a subcell inside the plant cell. The vacuole sap can be considered as the ICF of the vacuole, while the tonoplast can be considered as a membrane. Therefore, the $\mathrm{R}_{\mathrm{ICF}}$ in the equivalent circuit model of a plant cell with vacuoles will be replaced by another subcellular impedance block [73-74] in which the $\mathrm{R}_{\mathrm{ECF}}$ will be the $\mathrm{R}_{\mathrm{ICF}}$ because the cytoplasm could be considered the extracellular fluid of the vacuole. The 
equivalent circuit of biological cells can also be modeled with a number of other approaches $[1,75-76]$. The Nyquist plot, Cole-Cole plot [77-80], impedance equivalent circuit [81-82], Cole parameter estimation [75, 83-84] of electrical bioimpedance can be suitably utilized for tissue characterization [34, 85-86], body composition estimation [84] and disease detection [87]. It is worthwhile to note that the Cole-Cole plot is the Nyquist plot of complex permittivity [77-80] whereas the Cole plot is for complex impedance or admittance.

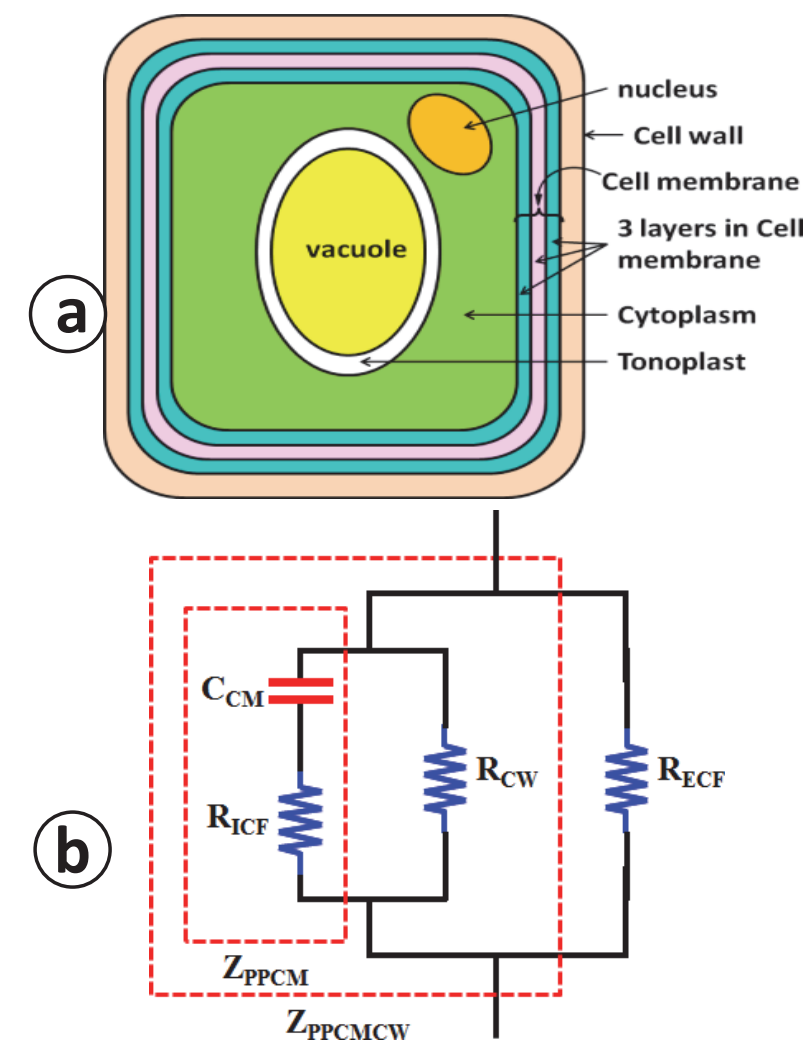

Fig.5: Equivalent electrical circuit modeling of plant cells. (a) The anatomy of an isolated plant cell showing intracellular fluids (ICF), extracellular fluids (ECF), the cell membrane (CM) and cell wall (CW). (b) An equivalent electrical circuit model of an isolated plant cell without considering tonoplast capacitance.

\subsection{Impedance Data Generation and Collection}

A number of impedance data sets were generated and collected to evaluate the performance of LEBISDI. They are described in Section 2.5. Artificial impedance data were simulated and experimental impedance data were collected from various combinations of high-precision resistors and capacitors. Finally, after evaluating and calibrating LEBISDI, we collected impedance data from fruit and vegetable tissues using an impedance analyzer.

The evaluation of the performance of LEBISDI therefore included three types of impedance data: (i) computer-simulated impedance data, (ii) data generated by EIS studies conducted on real electronic circuit components with an impedance analyzer and (iii) the data collected by EIS studies conducted on fruits and vegetables with an impedance analyzer. Data sets (i) and (ii) were used to evaluate LEBISDI, whereas data set (iii) was used to calculate the equivalent circuit parameter for studying the variation in bioimpedance parameters of different tissue compositions.

\subsubsection{PC-Based EIS Data Simulation in Matlab}

Different electronic circuit combinations were simulated (Fig. 6) and a number of impedance data sets were generated using a specially developed MATLAB-based electrical impedance data-generating program. The PCbased impedance data generator mathematically calculates complex impedance and its phase angles at a number of frequency points within a particular frequency band $(10 \mathrm{~Hz}$ to $2 \mathrm{MHz}$ ) for a number of circuit combinations called the simulated circuit model (SCM). Using the combinations of different circuit elements such as resistance (R), capacitance (C) and inductance (L), we could develop a capacitive circuit model (CCM) and an inductive circuit model (ICM). Figure 6 shows a few examples of the electronic circuit combinations studied; each has different values of resistance and capacitance connected in parallel and is tested to calculate the simulated impedance $\left(Z_{S}\right)$ within a specific frequency range.
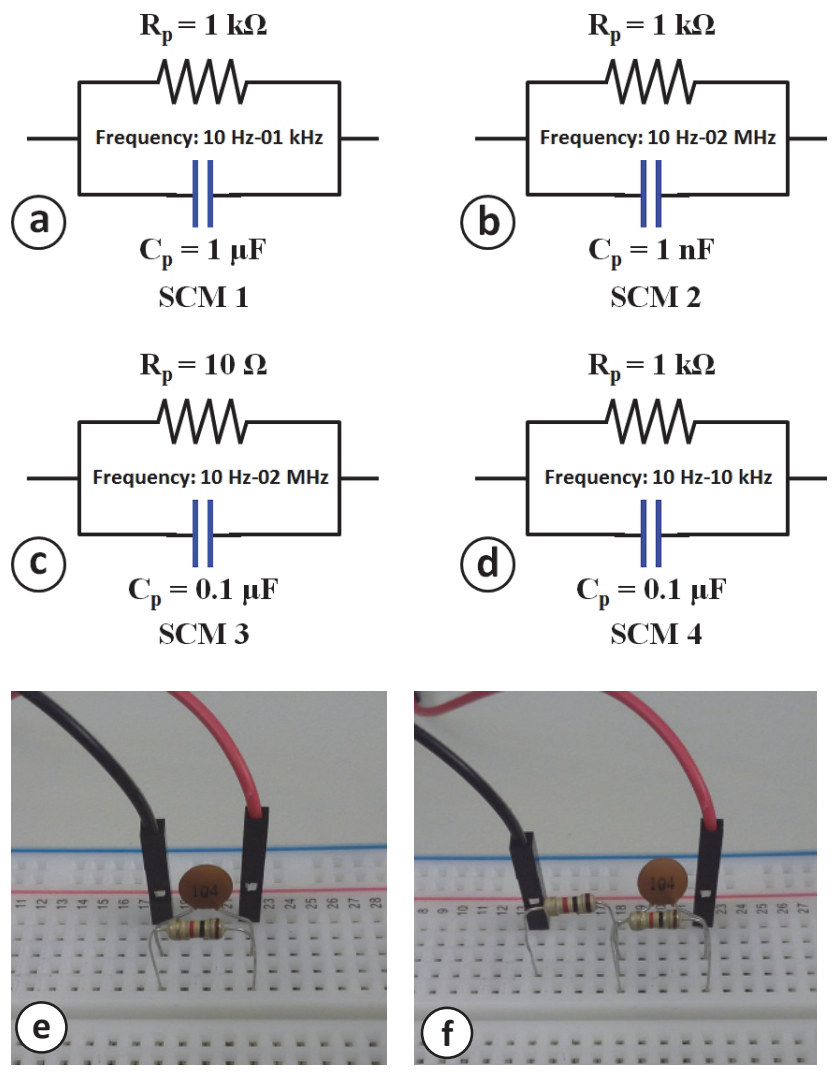

Fig.6: (a-d) Simulated circuit models developed with different electronic components and different circuit combinations of computer-simulated electrical impedance data. (e-f) Real circuit models developed with different circuit combinations of real electronic circuit components used for impedance data generation with an impedance analyzer. 
Real and imaginary parts of the simulated complex impedance obtained from all SCMs were calculated in the impedance data generator and stored in a .txt file in a desktop computer.

For a CCM made of a resistor and a capacitor connected in parallel, the real part of the impedance $\left(\mathrm{R}_{\mathrm{z}}\right)$ and the imaginary part of the impedance $\left(\mathrm{X}_{\mathrm{z}}\right)$ are respectively calculated as

$$
R_{z}=\frac{R\left(\frac{1}{\omega C}\right)^{2}}{R^{2}+\left(\frac{1}{\omega C}\right)^{2}}
$$

and

$$
X_{z}=\frac{R^{2}\left(\frac{1}{\omega C}\right)}{R^{2}+\left(\frac{1}{\omega C}\right)^{2}} .
$$

The modulus of the impedance and the phase angle $(\theta)$ are respectively calculated as

$$
|Z|=\sqrt{R_{z}^{2}+X_{z}^{2}}
$$

and

$$
\theta=-\arctan \left(\frac{X_{z}}{R_{z}}\right) .
$$

For the ICM of a resistor and inductor connected in parallel, the real part of the impedance $\left(\mathrm{R}_{\mathrm{z}}\right)$ and the imaginary part of the impedance $\left(\mathrm{X}_{\mathrm{z}}\right)$ are respectively calculated as

$$
R_{z}=\frac{R(\omega L)^{2}}{R^{2}+(\omega L)^{2}}
$$

and

$$
X_{z}=\frac{R^{2}(\omega L)}{R^{2}+(\omega L)^{2}}
$$

The modulus of the impedance and the phase angle $(\theta)$ are calculated using the formula as shown in the equations (13) and (14).

\subsubsection{EIS Data Collection from Real Electronic Circuits with an Impedance Analyzer}

Impedance data were also generated by conducting EIS studies on a real circuit model (RCM) developed with different circuit combinations of real electronic circuit components. A number of RCMs were developed with parallel and series-parallel combinations by high-precision resistors ( $1 \%$ tolerance) and capacitors ( $1 \%$ tolerance). EIS studies were conducted with a QuadTech7600 (QuadTech Inc., USA) impedance analyzer [88] using the four-probe technique [89-94]. The EIS study was conducted with circuit combinations by injecting a $1 \mathrm{~mA}$ constant sinusoidal current at different frequencies and the impedances and phase angles were measured at 100 discrete frequency points within a frequency band of $10 \mathrm{~Hz}$ to $2 \mathrm{MHz}$.

\subsubsection{EIS Data Collection from Fruits and Vegetables with an Impedance Analyzer}

The impedance responses of fruits and vegetables were studied by a four-electrode-method-based EIS using a QuadTech7600 impedance analyzer with a $1 \mathrm{~mA}$ constant sinusoidal applied current. The impedance variations in cucumber (Cucumis sativus), carrot (Daucus carota), pumpkin (Cucurbita mixta), bottle gourd (Lagenaria vulgaris), banana cortex or pseudo stem of the banana tree (Musa acuminata), potato (Solanum tuberosum), tomato (Lycopersicon Esculentum L), bringle (Solanum melongena), mango (Mangifera indica), apple (Malus domestica) and orange (Citrus sinensis) were studied to measure the $Z_{b}$ and $\theta_{b}$ at 100 discrete frequency points within a frequency band of $10 \mathrm{~Hz}$ to $2 \mathrm{MHz}$.

Nyquist plots were obtained from $\mathrm{R}_{\mathrm{z}}$ and $\mathrm{X}_{\mathrm{z}}$ which were calculated from $\mathrm{Z}$ and $\theta$. QuadTech 7000-04 alligator clip leads (QuadTech Inc., USA), which are generally used to connect to large multiterminal devices, were used [88] as an interface between the surface electrodes and the impedance analyzer. The QuadTech 7000-04 comprises a BNC-to-BNC cable, four banana plug adapters and four alligator clips, which easily connect to metal conductors and electrodes. Figure 7 a presents a schematic of the fourprobe-method-based impedance data collection, which shows the arrangement of the current and voltage electrodes used for the EIS studies we conducted on circuit combinations. Figure $7 \mathrm{~b}$ presents an EIS data collection schematic of the four-electrode-method-based EIS studies conducted on fruit and vegetable samples with separate current and voltage electrodes. As shown in the Figure $7 \mathrm{~b}$, the current signal is injected through the outer driving electrodes (red rectangles) and the voltage data are measured across the inner sensing electrodes (blue rectangles).

Circuit element studies were performed by directly connecting 7000-04 alligator clips with the circuit leads. EIS for fruit and vegetable samples required that the lead set was used with an ECG electrode-based four-electrode array (EE-FEA). Four QuadTech solid gel Ag/AgCl ECG electrodes were fixed on sticky insulating tape and the EEFEA was developed (Figure 8a). The voltage electrodes were placed between current electrodes, with a distance of $50 \mathrm{~mm}$ between voltage electrodes (Figure 8a). In addition, the distance between the current-electrode and the voltage- 
electrode was maintained by separating the voltage electrodes from the current electrodes by $25 \mathrm{~mm}$ (Figure $8 \mathrm{a})$. Fruit and vegetable tissue health and temperature were varied in different EIS studies, whereas the amplitude (1mA r.m.s.) remained constant and the sinusoidal current varied from $10 \mathrm{~Hz}$ to $2 \mathrm{MHz}$ (Figure $8 \mathrm{~b}$ ).

Prior to EIS studies, all fruits and vegetables were properly cleaned and marked for electrode placement using a measuring tape, and the electrode array was pasted on the skin of the cleaned samples. The QuadTech7000-04 alligator connectors of the impedance analyzer probe were connected to the electrodes by EE-FEA. During EIS studies, $Z$ and $\theta$ were set as the primary and secondary parameters, respectively, in the impedance analyzer, and measured at 100 frequency points within $10 \mathrm{~Hz}$ to $2 \mathrm{MHz}$. To study the effect of storage time on vegetable bioimpedance, we conducted EIS studies every 3 days for 22 days on the same samples with the same instrumental setup. To study variation in biological tissue impedance profiles due to boiling, we conducted EIS studies on fruits and vegetables before and after boiling.

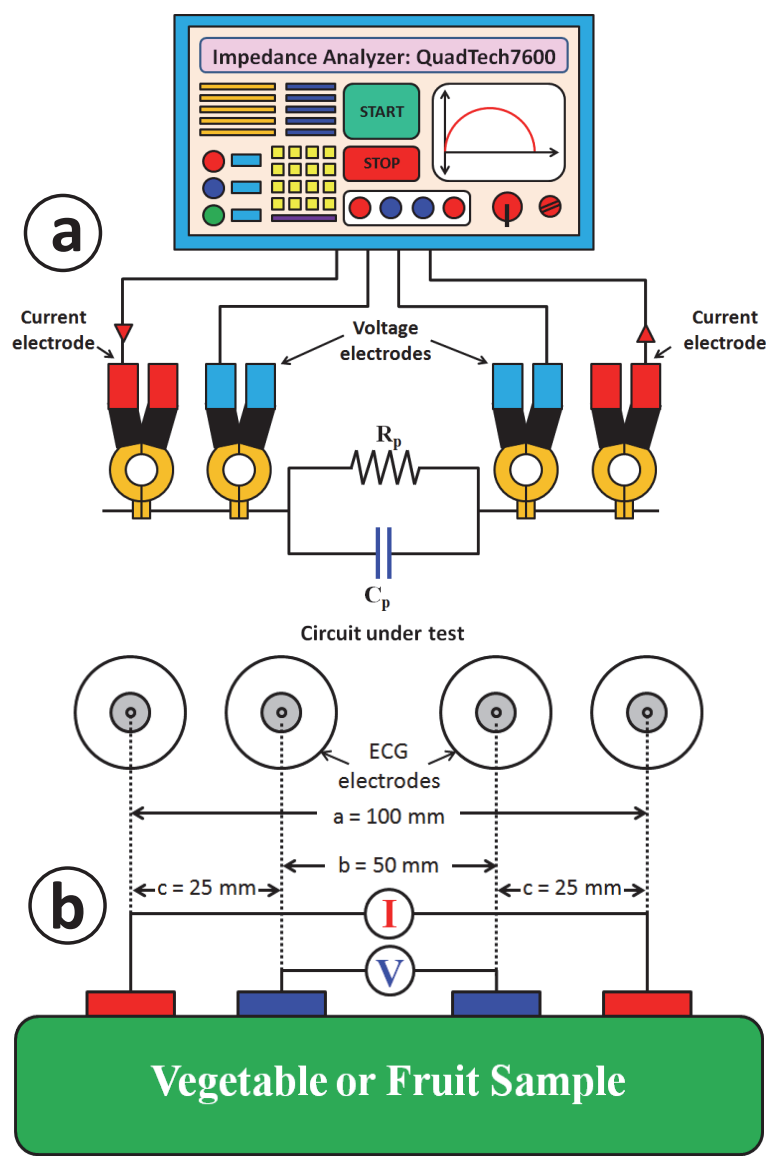

Fig.7: EIS data collection with the four-probe method using an impedance analyzer. (a) A schematic of the electronic circuit elements in the EIS data collection using the QuadTech7600 impedance analyzer. (b) A schematic of EIS data collection from fruit and vegetable tissues.

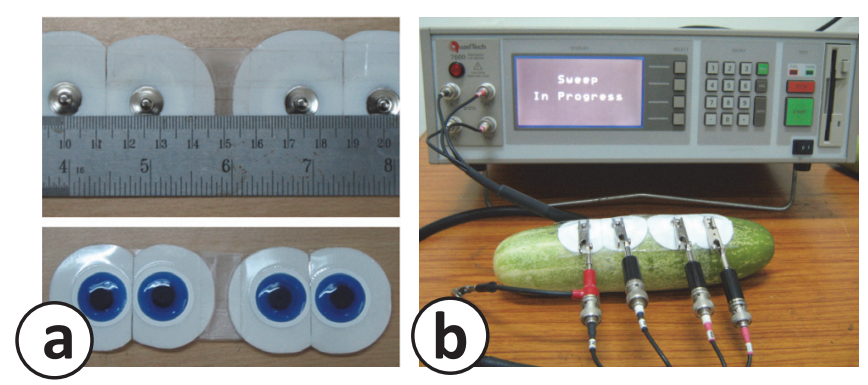

Fig.8: EIS studies on fruits and vegetables using the QuadTech7600 impedance analyzer and ECG electrodes. (a) The ECG electrode-based four-electrode array (EE-FEA) used for EIS studies on fruits and vegetables. (b) EIS studies on fruits and vegetables using the QuadTech7600 impedance analyzer.

\subsection{LabVIEW-Based Electrical Bioimpedance Spectro- scopic Data Interpreter (LEBISDI)}

The LabVIEW-based electrical bioimpedance spectroscopic data interpreter (LEBISDI) has been developed to study the equivalent circuit parameters of biological tissues using the LabVIEW 2014 software. The NI LabVIEW is a highly productive software development environment that enables the user to obtain a graphical programing and unprecedented hardware integration facility. LabVIEW provides a rapid virtual instrumentation design facility required for the high-speed and highly sophisticated measurement and control system applications. The proposed LEBISDI has been developed with a circle-fitting algorithm and the R-X data are fit to a circular arc from which the center and radius of the circle are calculated. Using the coordinates of the circle's center, the radius and the other impedance parameters $\left(Z_{b}, \theta_{b}, R_{z}\right.$ and $\left.X_{z}\right)$ are calculated. Figures $9 \mathrm{a}$ and $\mathrm{b}$ show LabVIEW-based graphical user interface (GUI) of the LEBISDI and the Nyquist plot loaded into the LEBISDI respectively.

The impedance data is fed to the LEBISDI as a matrix $\left[\mathrm{M}_{\mathrm{z}}\right]_{100 \times 3}$ having three columns: $\mathrm{f}, \mathrm{R}_{\mathrm{z}}$ and $\mathrm{X}_{\mathrm{z}}$ respectively. The impedance data matrix $\left[\mathrm{M}_{\mathrm{z}}\right]$ is saved in a .txt file though the program and can be easily modified to work with .xls file also. All the 100 rows are the $f, R_{z}$ and $X_{z}$ data obtained for a particular frequency point $f_{n}$. For each frequency data points $\left(f_{n}\right)$, the real $\left(R_{z}\left(f_{n}\right)\right)$ and imaginary $\left(\mathrm{X}_{\mathrm{z}}\left(\mathrm{f}_{\mathrm{n}}\right)\right)$ parts of the impedance data are calculated from $\mathrm{Z}_{\mathrm{n}}$ and $\theta_{\mathrm{n}}$ obtained from the EIS and then are loaded through the GUI of the LEBISDI (Figure 9b) by pressing the "LOAD FILE" button. After that, the "FIT A CIRCLE" button of the LEBISDI GUI is pressed to fit the data along a circular path and the series resistance, parallel resistance, constant phase elements, $\mathrm{X}_{\mathrm{Max}}$ (the maximum value of $\mathrm{X}_{\mathrm{z}}$ ) and $X_{M a x}$ frequency (i.e., the characteristic frequency $\left(f_{c}\right)$ ) are calculated. 

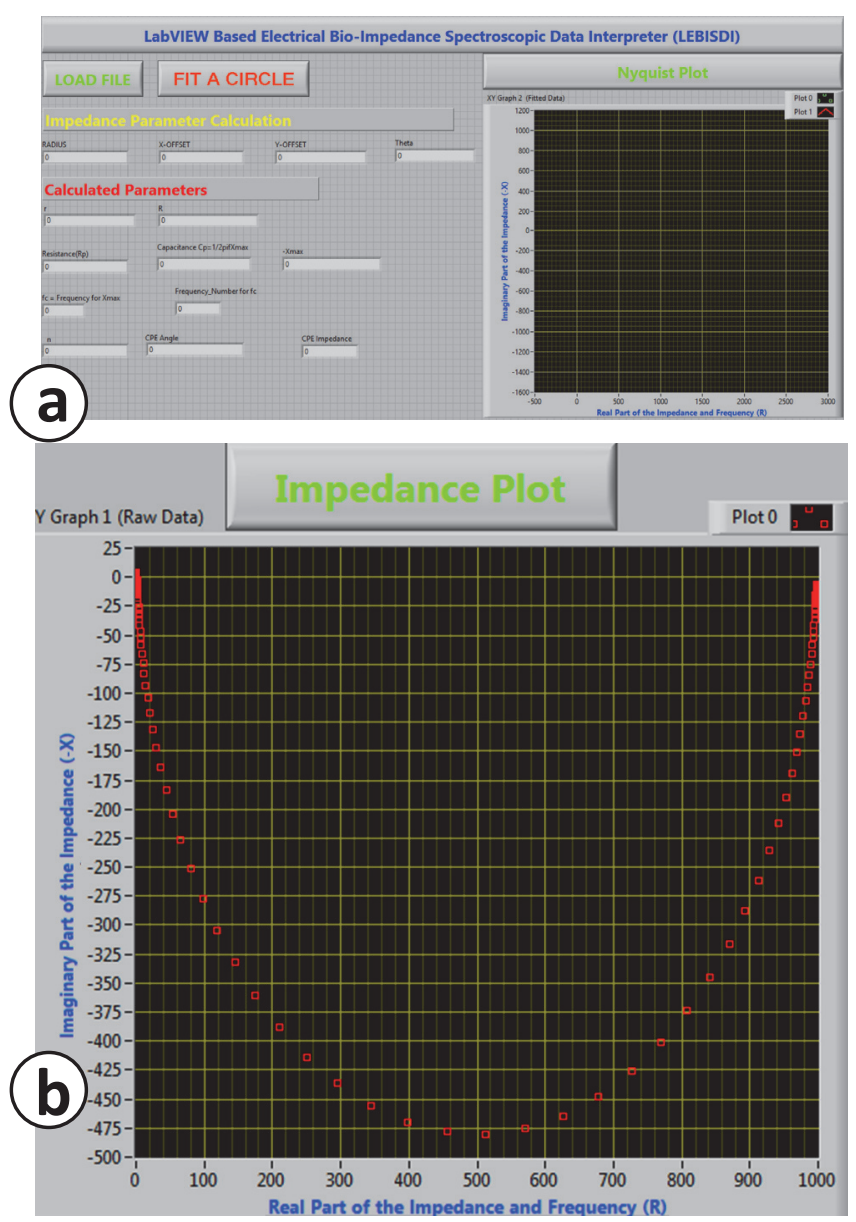

Fig.9: The LabVIEW-based GUI of the LEBISDI and impedance data loaded in LEBISDI. (a) GUI of LEBISDI and (b) the Nyquist plot obtained in LEBISDI after loading real and imaginary impedance data.

\section{Results}

\subsection{LEBISDI Evaluation with Simulated Data}

The real and imaginary parts of the simulated impedance data sets were calculated and Nyquist plots were drawn (Figure 10) in the Matlab-based impedance data generator. The real and imaginary parts of impedance were also stored in a .txt file for use with the LEBISDI assessment. The R-X data corresponding to each frequency point were loaded in LEBISDI (Figure 11) from the .txt file and the Nyquist plots are obtained in the GUI.

The Nyquist plots drawn from the real and imaginary parts of the simulated impedance were fitted in LEBISDI to calculate the values of the elements in the circuit combination used in the computer simulation. Impedance parameters calculated by LEBISDI were compared with the actual values of the circuit components used for impedance data simulation to assess the performance of LEBISDI.

Figure 12 shows that the LEBISDI successfully fit the Nyquist plots obtained for all four of the simulated circuit models shown in Figure 6 and accurately calculated the electronic circuit parameters (Table 1). Results from LEBISDI show that the errors found in $\mathrm{R}_{\mathrm{p}}$ identification for simulated circuit models $1,2,3$ and 4 were $0.0027 \%$, $0.0187 \%, 0.0188 \%$ and $0.0030 \%$, respectively, and 0.937 $\%, 0.068 \%, 0.068 \%$ and $0.569 \%$, respectively, for $\mathrm{C}_{\mathrm{p}}$ calculations (Table 1). Results also demonstrate that $n$ (power in the CPE model) was equal to 1, indicating that there was no CPE in the designed models, which agrees with results for the simulated models.

The impedance data obtained from the inductive circuit models are also analyzed with LEBISDI. The Nyquist plots obtained from the data simulator were loaded and fitted in LEBISDI and the impedance parameters used in the computer simulation, such as parallel resistance $\left(R_{p}\right)$ and parallel inductance $\left(\mathrm{L}_{\mathrm{p}}\right)$, were calculated. The results obtained from the simulated data analysis of the inductive circuit are presented in Figure 13 and Table 2.
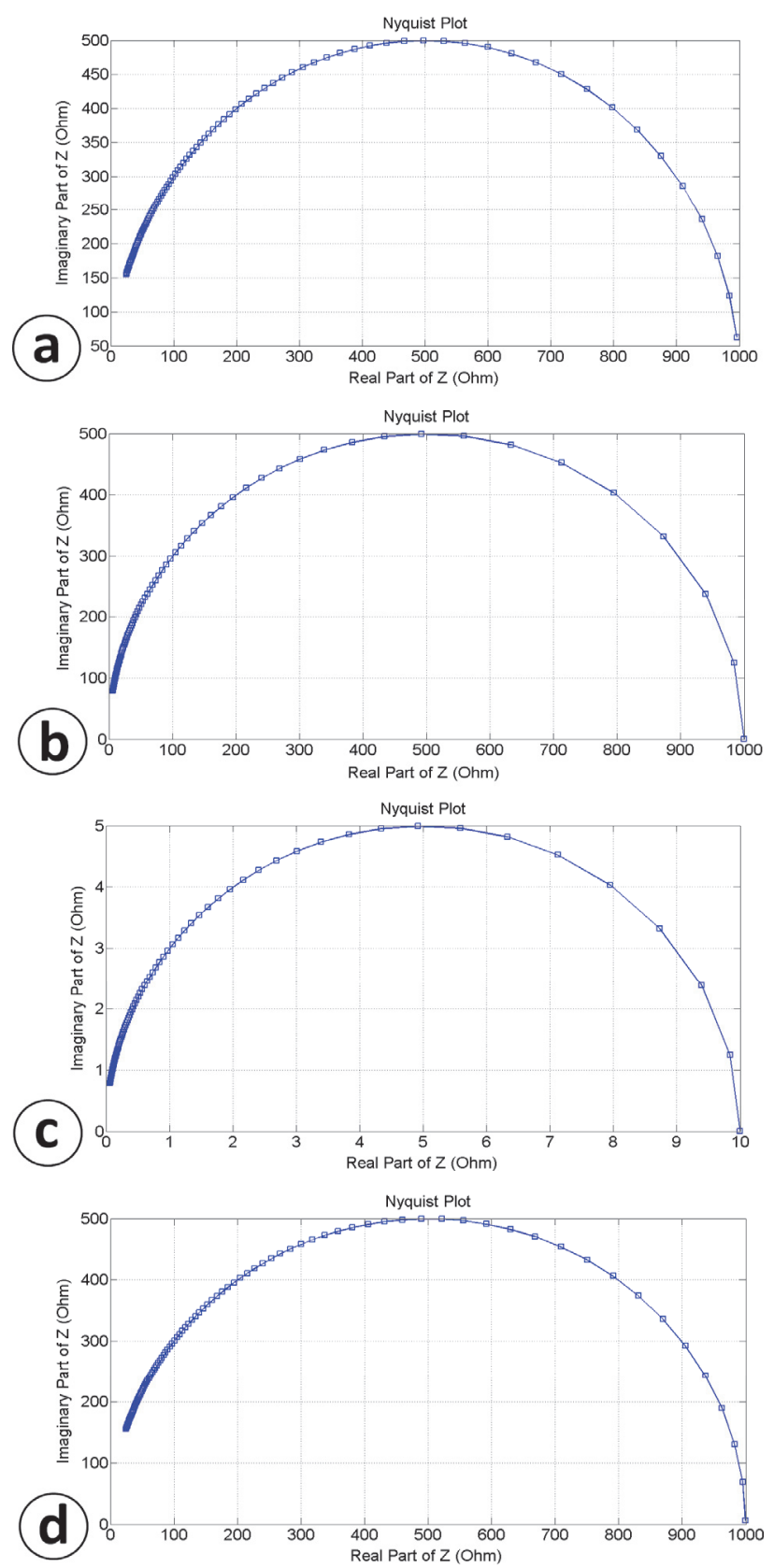

Fig.10: Nyquist plots obtained from computer simulations on $\mathrm{CCM}$ in the Matlab-based impedance data generator. 


\subsection{LEBISDI Evaluation with Data Collected from Real Circuit Components}

Next, we investigated the performance of LEBISDI with the impedance data generated by the RCM developed with different circuit combinations of real electronic circuit components. Nyquist plots obtained from the real circuit data collected by an impedance analyzer were fitted by LEBISDI (Figure 14) and the impedance parameters were calculated. Figure 14a shows the impedance plots of RCM 1 , which is a parallel combination of a $1 \mathrm{k} \Omega$ resistor and a $0.1 \mu \mathrm{F}$ capacitor. Table 3 shows the impedance parameters calculated by LEBISDI for RCM 1 and the error obtained in the fitting. The errors were $0.348 \%$ and $0.01 \%$ for resistance and capacitance calculations, respectively (Table 3).

Impedance data were also collected from a parallel combination of a $2 \mathrm{k} \Omega$ resistor and a $0.1 \mu \mathrm{F}$ capacitor called RCM 2. Figure $14 \mathrm{~b}$ shows the impedance plots for RCM 2 and Table 4 presents the impedance parameters calculated by LEBISDI for this circuit. The errors in the fitting process in LEBISDI were $0.335 \%$ and $5.0 \%$ for resistance and capacitance calculations, respectively (Table 4).
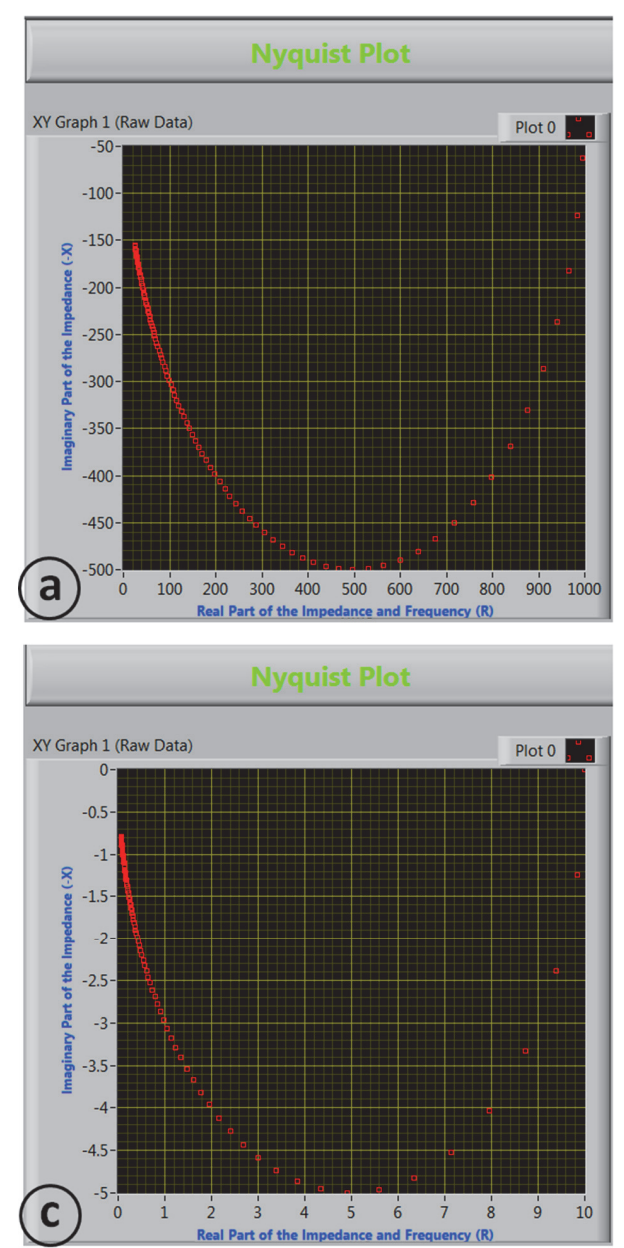

\subsection{LEBISDI Evaluation with Data Collected from Fruits and Vegetables}

Impedance data were also collected from fruits and vegetables. Figure $15-17$ show the impedance plots of a cucumber, a carrot and a bottle gourd, respectively. Numerical results for these configurations are reported in Table 5. To investigate the effect of boiling on impedance, data were also collected from the fruits and vegetables before and after boiling. Figures $18 \mathrm{a}$ and $\mathrm{b}$ show the impedance plots of a green banana before and after boiling, respectively. Numerical results for these configurations are reported in Table 6. After boiling, impedance parameters were lower for both series and parallel resistance, likely because boiling destroyed the structure of the cells; the CPE angle was also reduced. We investigated the role of freshness on impedance variation by collecting data from naturally stored vegetables. Impedance was measured daily and the variation over time was analyzed by LEBISDI. Figure 19 shows the impedance plots of a cucumber collected every 3 days for 22 days, and Table 7 shows the impedance parameters calculated by LEBISDI of impedance in a cucumber throughout the 22-day storage period. Over time, the impedance parameters for parallel resistance gradually increased while the impedance parameters for series resistance and parallel capacitance gradually decreased, likely due to dehydration with storage time; the CPE angle also increased slightly with time.
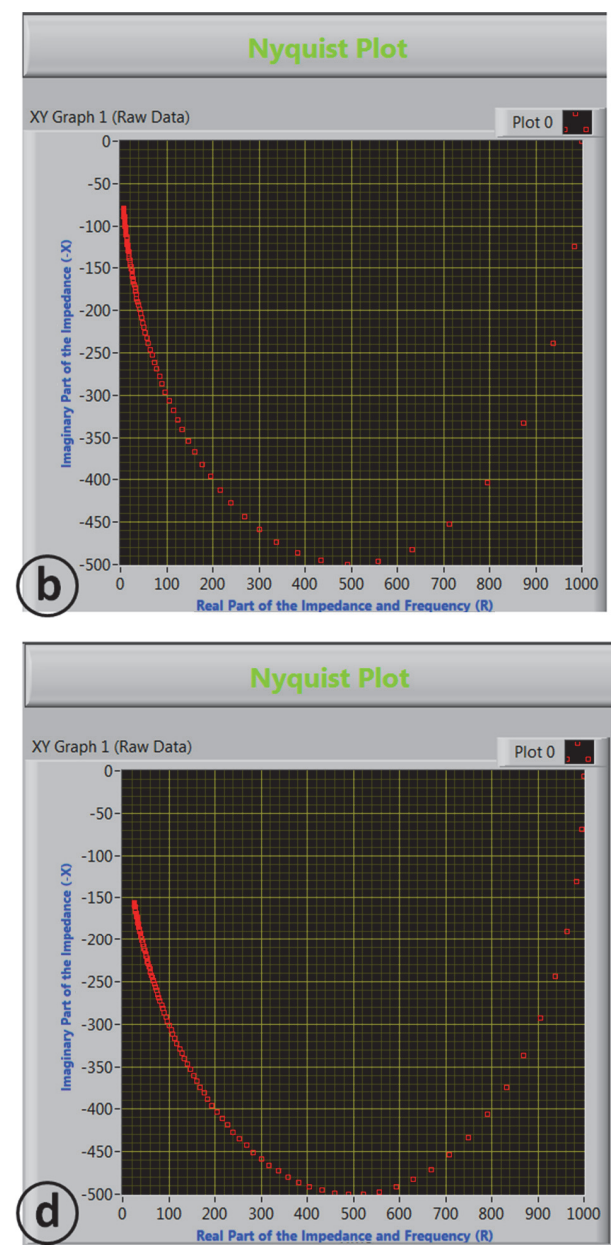

Fig.11: Nyquist plots of simulated impedance data loaded in the GUI of LEBISDI. 

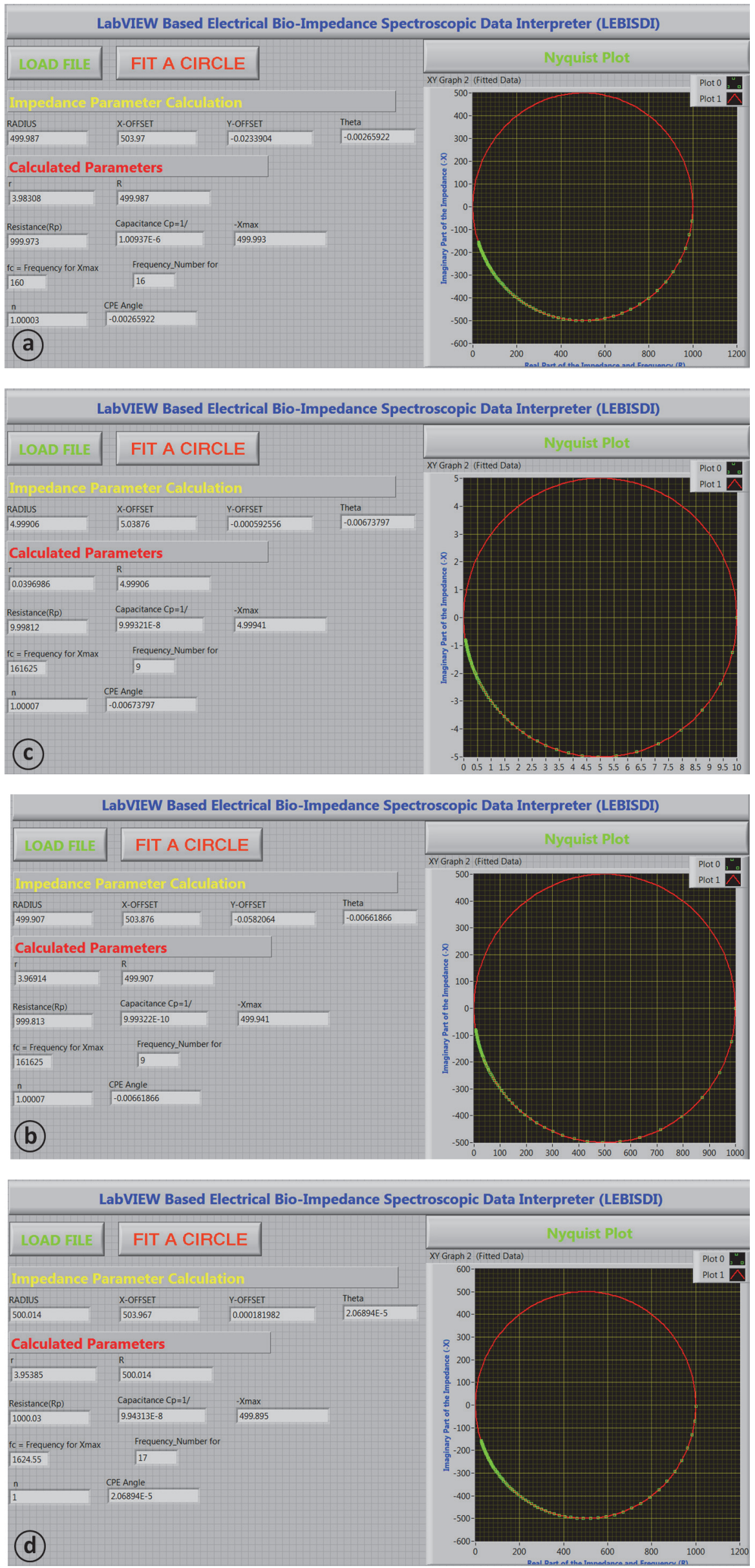

Fig.12: Nyquist plots of simulated (capacitive) impedance loaded in LEBISDI after fitting. 

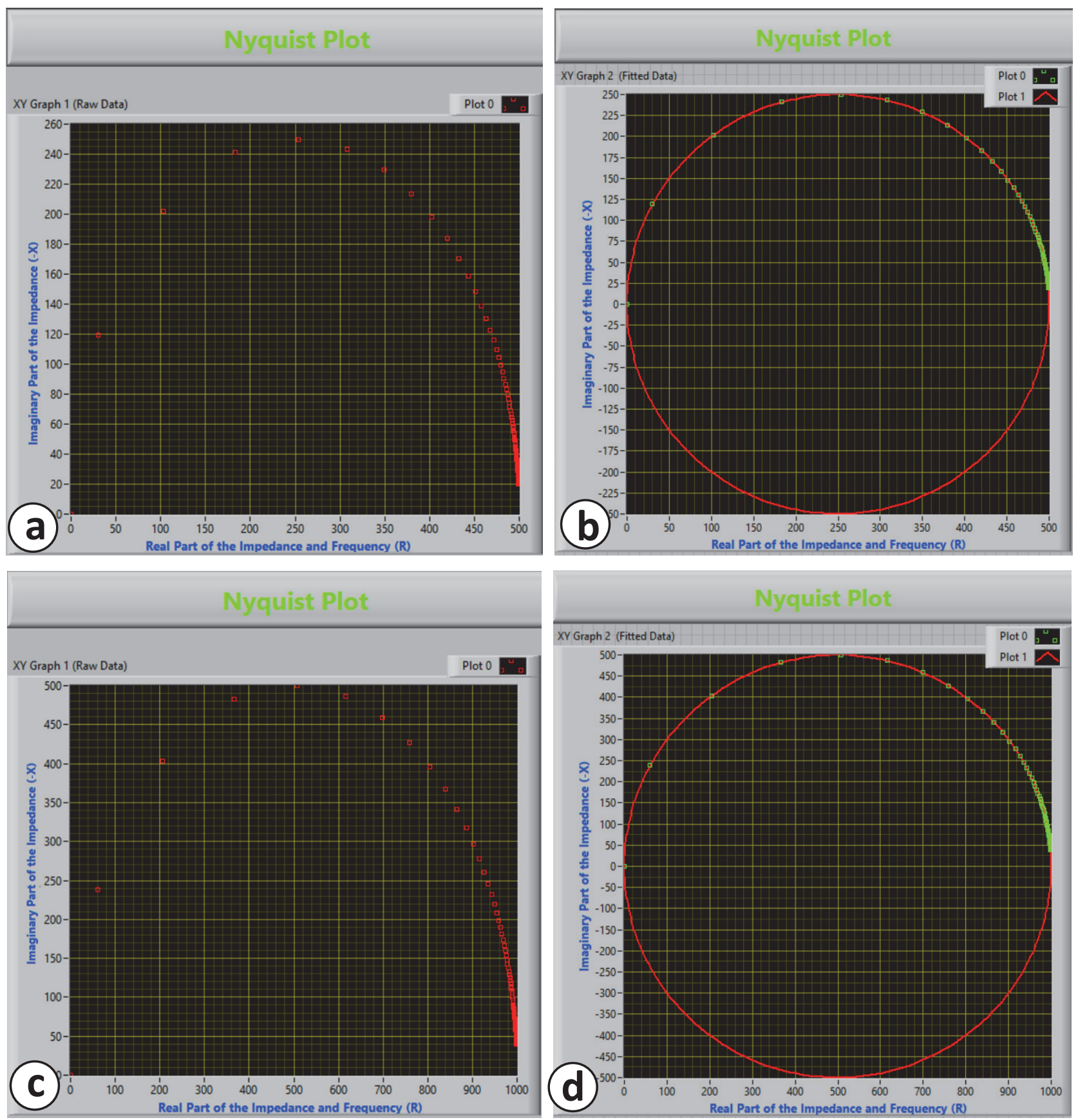

Fig.13: Nyquist plots of simulated (inductive) impedance data loaded in LEBISDI after fitting.

Table 1: Impedance parameters and errors calculated by LEBISDI for the capacitive circuit models (CCM) studied.

\begin{tabular}{llllll}
\hline SCM & Frequency (f) & $\mathbf{R}_{\mathbf{p}}(\boldsymbol{\Omega})$ & $\mathbf{C}_{\mathbf{p}}(\mathbf{F})$ & Error $\mathbf{R}_{\mathbf{p}}$ & Error $\mathbf{C}_{\mathbf{p}}$ \\
\hline SCM 1 & $10-1 \mathrm{kHz}$ & 0999.97 & $1.01 \mathrm{E}-06$ & $0.0027 \%$ & $0.937 \%$ \\
SCM 2 & $10-2 \mathrm{MHz}$ & 0999.81 & $9.99 \mathrm{E}-10$ & $0.0187 \%$ & $0.068 \%$ \\
SCM 3 & $10-2 \mathrm{MHz}$ & 9998.12 & $9.99 \mathrm{E}-08$ & $0.0188 \%$ & $0.068 \%$ \\
SCM 4 & $10-10 \mathrm{kHz}$ & 1000.03 & $9.94 \mathrm{E}-08$ & $0.0030 \%$ & $0.569 \%$ \\
\hline
\end{tabular}

Table 2: Impedance parameters and errors calculated by LEBISDI for the inductive circuit models (ICM) studied.

\begin{tabular}{llllll}
\hline SCM & Frequency $(\mathbf{f})$ & $\mathbf{R}_{\mathbf{p}}(\boldsymbol{\Omega})$ & $\mathbf{L}_{\mathbf{p}}(\mathbf{H})$ & Error $\mathbf{R}_{\mathbf{p}}$ & Error $\mathbf{L}_{\mathbf{p}}$ \\
\hline SCM 5 & $10-2 \mathrm{MHz}$ & 499.98 & $09.85 \mathrm{E}-4$ & $0.0032 \%$ & $1.496 \%$ \\
SCM 6 & $10-2 \mathrm{MHz}$ & 999.97 & $19.70 \mathrm{E}-4$ & $0.0031 \%$ & $1.497 \%$ \\
\hline
\end{tabular}



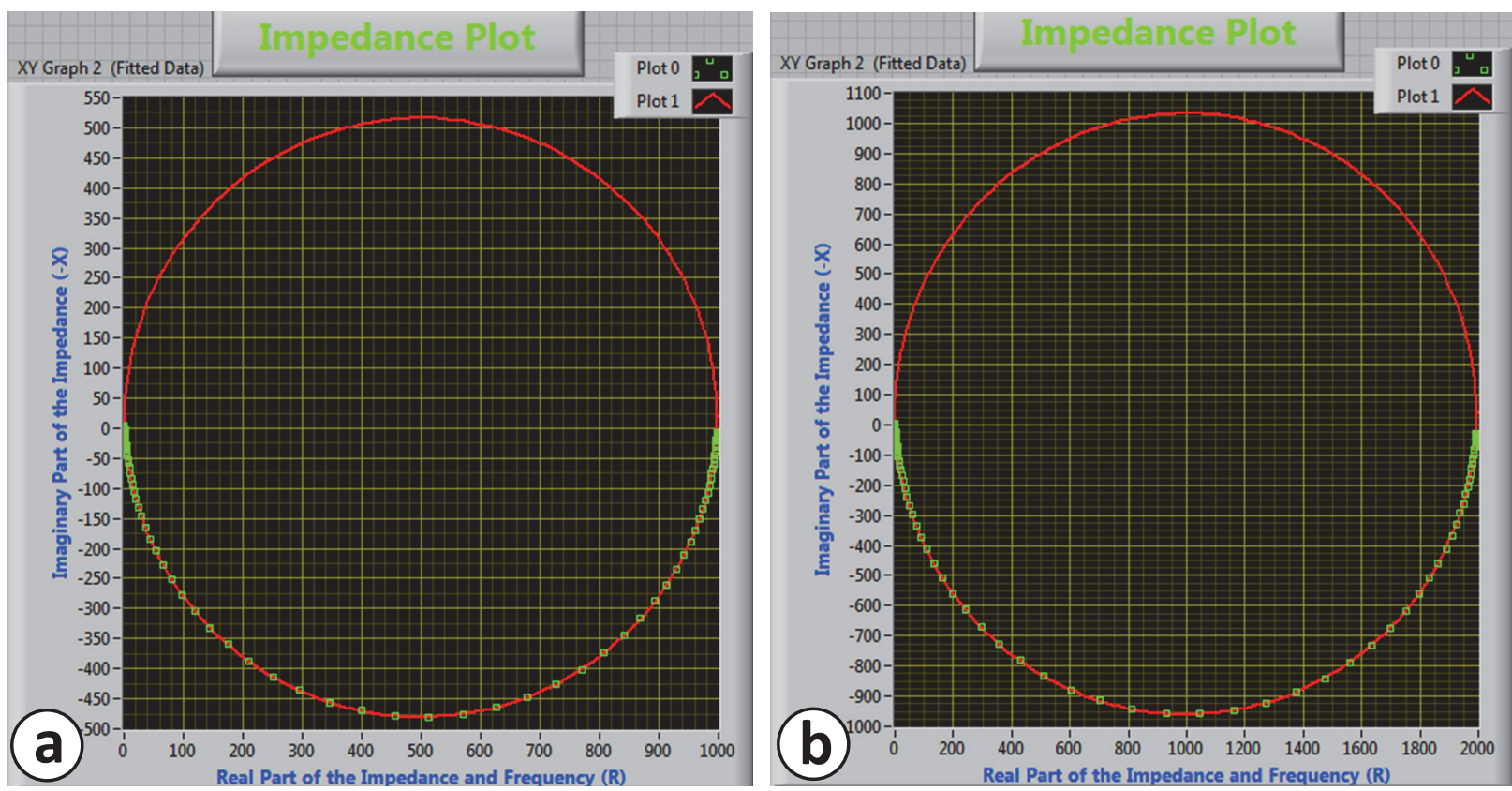

Fig.14: Interpretation of the impedance data obtained from real electronic circuit combinations (RCMs) using LEBISDI. (a) Data interpretation for RCM 1, which was a parallel combination of a $1 \mathrm{k} \Omega$ resistor and a $0.1 \mu \mathrm{F}$ capacitor. (b) Data interpretation for RCM 2, which was a parallel combination of a $2 \mathrm{k} \Omega$ resistor and a $0.1 \mu \mathrm{F}$ capacitor.

Table 3: Comparison of actual impedance data and the data obtained from LEBISDI for RCM 1 containing a $1 \mathrm{k} \Omega$ resistor and a $0.1 \mu \mathrm{F}$ capacitor in parallel.

\begin{tabular}{lll}
\hline Values & Resistor $(\boldsymbol{\Omega})$ & Capacitor $(\mu \mathrm{F})$ \\
\hline Original & 1000.00 & 0.10 \\
Calculated & 0996.52 & 0.10 \\
Error & $0.348 \%$ & $0.0885 \%$ \\
\hline
\end{tabular}

Table 4: Comparison of actual impedance data and the data obtained from LEBISDI for RCM 2 containing a $2 \mathrm{k} \Omega$ resistor and a $0.1 \mu \mathrm{F}$ capacitor in parallel.

\begin{tabular}{lll}
\hline Values & Resistor & Capacitor \\
\hline Original & $2000.00 \Omega$ & $0.10 \mu \mathrm{F}$ \\
Calculated & $1993.27 \Omega$ & $0.10 \mu \mathrm{F}$ \\
Error & $0.335 \%$ & $4.993 \%$ \\
\hline
\end{tabular}

Table 5: Impedance data obtained from LEBISDI for a cucumber, a carrot and a bottle gourd.

\begin{tabular}{llll}
\hline Parameters & Cucumber & Carrot & Bottle Gourd \\
\hline $\mathrm{r}$ & $19.17 \Omega$ & $-11.68 \Omega$ & $57.38 \Omega$ \\
$\mathrm{R}$ & $1437.05 \Omega$ & $1838.85 \Omega$ & $2115.34 \Omega$ \\
$\mathrm{C}$ & $0.34 \mu \mathrm{F}$ & $0.08 \mu \mathrm{F}$ & $0.17 \mu \mathrm{F}$ \\
$\mathrm{X}_{\mathrm{Max}}$ & $-463.13 \Omega$ & $-583.07 \Omega$ & $-636.83 \Omega$ \\
$\mathrm{f}_{\mathrm{c}}$ & $4204.70 \mathrm{~Hz}$ & $14427 \mathrm{~Hz}$ & $6086.60 \mathrm{~Hz}$ \\
$\theta_{\mathrm{CPE}}$ & $19.26^{\circ}$ & $20.16^{\circ}$ & $20.93^{\circ}$ \\
$\mathrm{n}$ & 0.79 & 0.78 & 0.77 \\
\hline
\end{tabular}

Table 6: Comparison of the impedance parameters obtained from the impedance data estimation in LEBISDI for a green banana before and after boiling.

\begin{tabular}{lll}
\hline Parameters & Unboiled & Boiled \\
\hline $\mathrm{r}$ & $-354.08 \Omega$ & $309.04 \Omega$ \\
$\mathrm{R}$ & $9382.64 \Omega$ & $150.66 \Omega$ \\
$\mathrm{C}$ & $0.048 \mu \mathrm{F}$ & $0.05 \mu \mathrm{F}$ \\
$\mathrm{X}_{\mathrm{Max}}$ & $-2412.03 \Omega$ & $-46.00 \Omega$ \\
$\mathrm{f}_{\mathrm{c}}$ & $6896.98 \mathrm{~Hz}$ & $286206 \mathrm{~Hz}$ \\
$\theta_{\mathrm{CPE}}$ & $28.26^{\circ}$ & $4.379^{\circ}$ \\
$\mathrm{n}$ & 0.69 & 0.959 \\
\hline
\end{tabular}



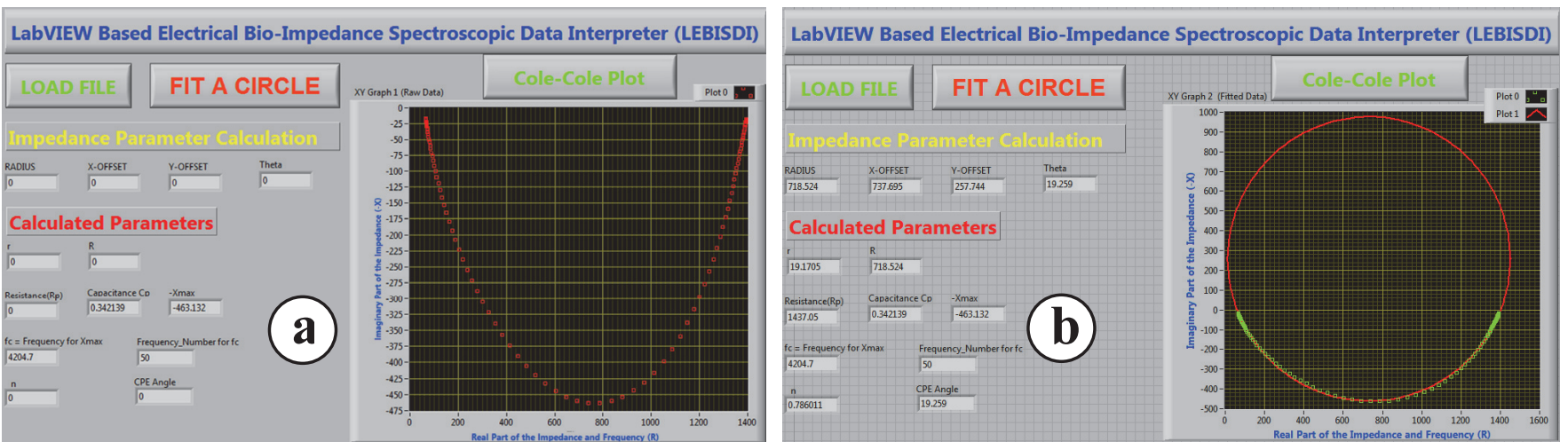

Fig.15: Impedance data fitting and analysis in LEBISDI for a cucumber. (a) Before fitting: data loaded. (b) After fitting: data calculated.
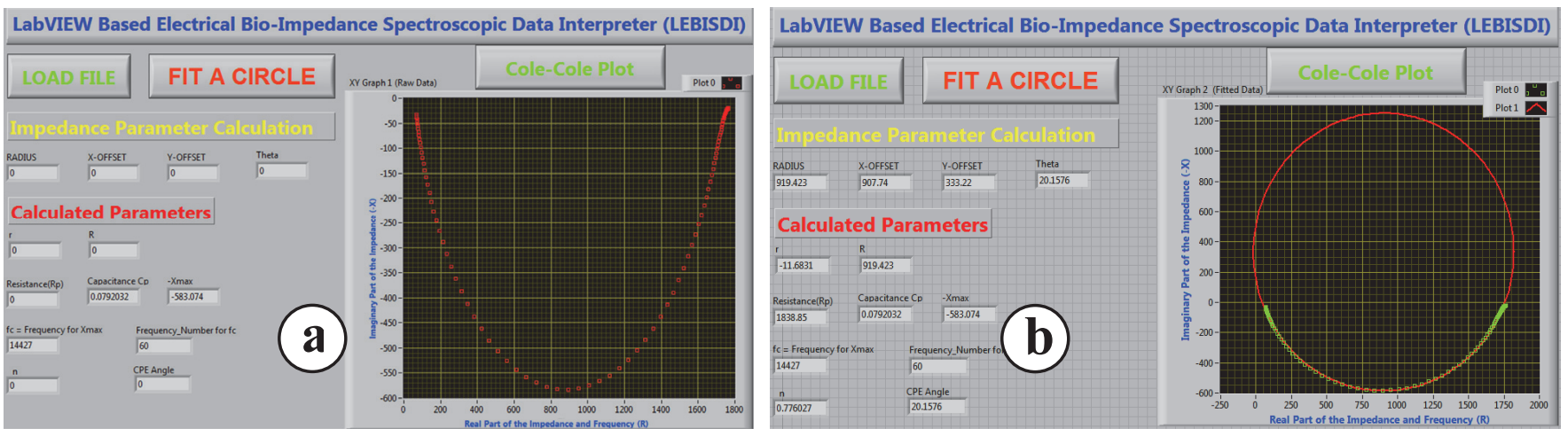

Fig.16: Impedance data fitting and analysis in LEBISDI for a carrot. (a) Before fitting: data loaded. (b) After fitting: data calculated.
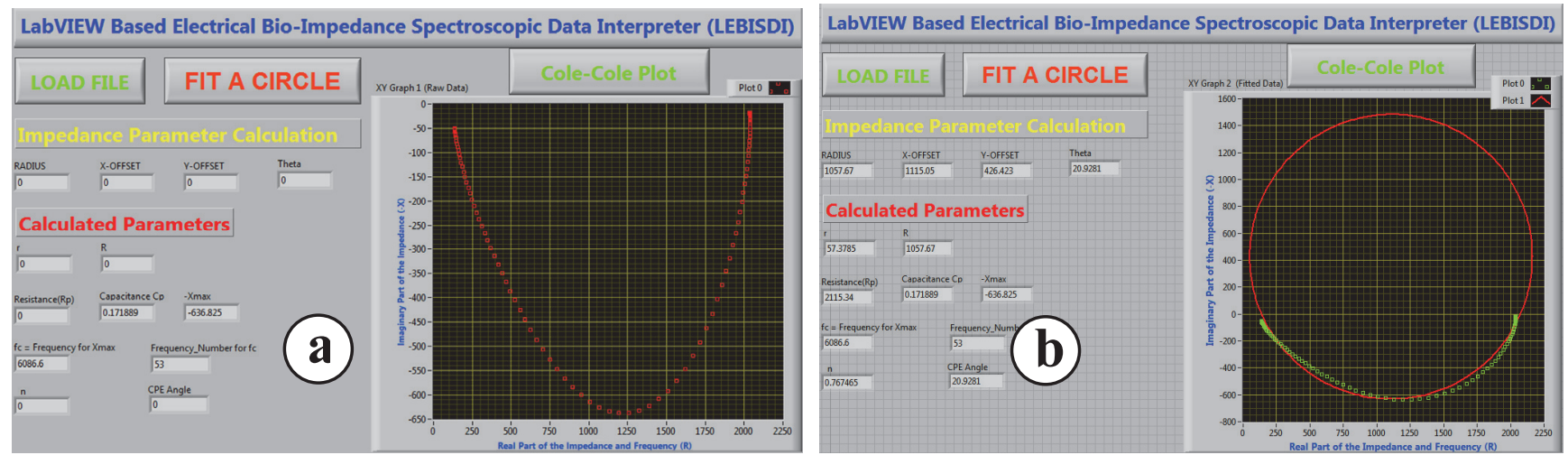

Fig.17: Impedance data fitting and analysis in LEBISDI for a bottle gourd. (a) Before fitting: data loaded. (b) After fitting: data calculated.
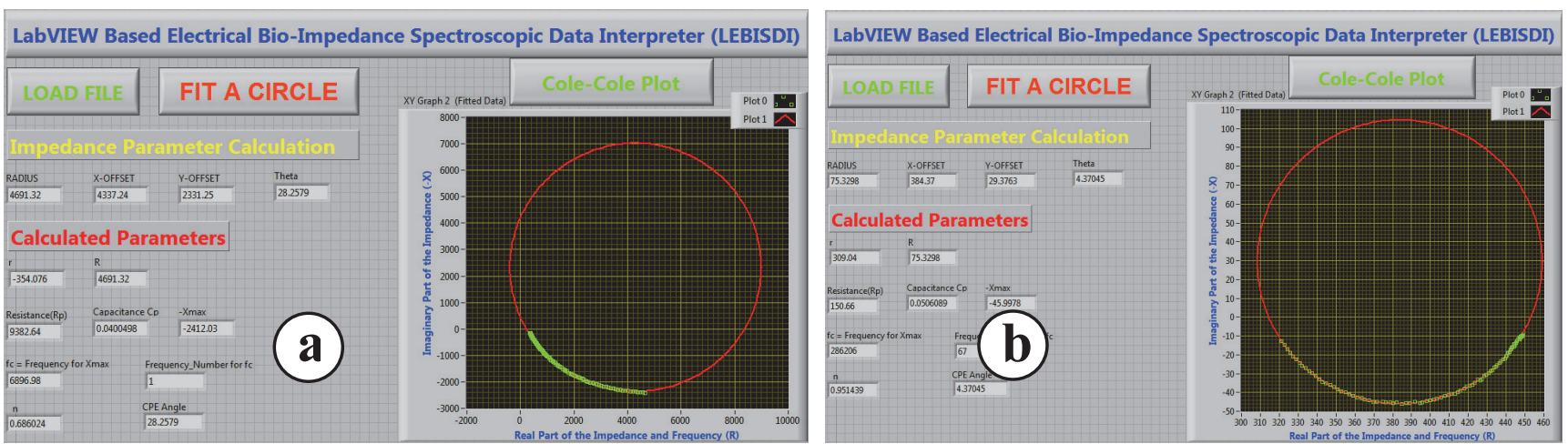

Fig.18: Analysis of the variation in the impedance data obtained from the impedance parameter in LEBISDI for a green banana (a) before and (b) after boiling. 
Table 7: Comparison of impedance parameters calculated from the impedance data estimation in LEBISDI for cucumber sample studied over a 22 -day period.

\begin{tabular}{llllllll}
\hline Day & $\mathbf{r}(\Omega)$ & $\mathbf{R}(\Omega)$ & $\mathbf{C}(\boldsymbol{\mu F})$ & $\mathbf{X}_{\text {Max }}(\Omega)$ & $\mathbf{F c}(\mathbf{H z})$ & $\boldsymbol{\theta}_{\mathbf{C P E}}$ & $\mathbf{n}$ \\
\hline 1 & 19.17 & 1437.05 & 0.34 & -463132 & 4204.70 & $19.26^{\circ}$ & 0.79 \\
4 & 12.43 & 1660.37 & 0.30 & -529.34 & 4204.70 & $19.94^{\circ}$ & 0.78 \\
7 & -0.26 & 1940.84 & 0.29 & -617.50 & 3717.00 & $20.27^{\circ}$ & 0.78 \\
10 & -6.14 & 2190.62 & 0.26 & -698.48 & 3717.00 & $20.34^{\circ}$ & 0.78 \\
13 & -14.74 & 2289.29 & 0.22 & -723.66 & 4204.70 & $20.81^{\circ}$ & 0.77 \\
16 & -29.27 & 2385.08 & 0.22 & -735.05 & 4204.70 & $22.09^{\circ}$ & 0.75 \\
19 & -37.05 & 2447.67 & 0.21 & -735.37 & 4204.70 & $22.98^{\circ}$ & 0.75 \\
22 & -45.29 & 2698.61 & 0.19 & -819.45 & 4204.70 & $22.76^{\circ}$ & 0.75 \\
\hline
\end{tabular}
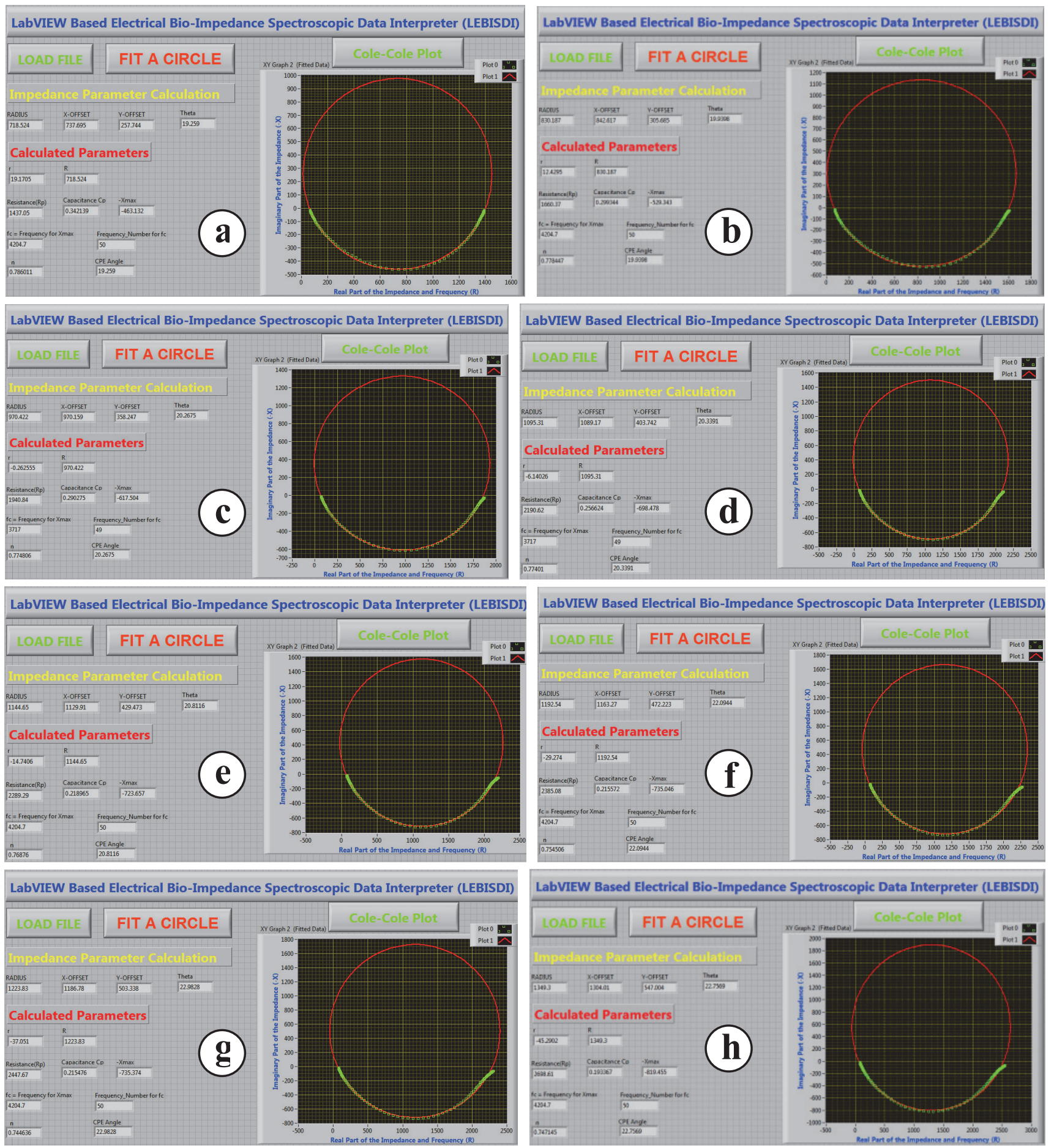

Fig.19: Impedance plots obtained for a cucumber over a 22-day storage period using a LEBISDI to show the variation in the impedance parameters for naturally stored vegetables: (a) day 1, (b) day 4, (c) day 7, (d) day 10, (e) day 13, (f) day 16, (g) day 19 and (h) day 22. 


\section{Discussion}

LEBISDI software can be suitably used for analyzing the bioimpedance data for noninvasive biological tissue characterization. The present study is mainly associated with the vegetable tissues though the analysis of human tissue impedance data can be successfully conducted with the proposed software. As a future direction the proposed LEBISDI program can also be applied for human tissue characterization for health analysis and disease diagnosis. LEBISDI can also be potentially applied for multifrequency bioelectrical impedance analysis (BIA) based tissue composition assessment, electrical impedance-based tissue characterization and [95-96] or disease diagnosis [97-98] and EIS based tissue health characterization in biological, biomedical, medical and clinical applications [99-106].

\section{Conclusions}

Under alternating electrical excitation, biological tissues produce a complex bioelectrical impedance that varies over a wide band of frequencies. By identifying the frequency response of a tissue's electrical impedance, we can identify the equivalent electrical circuit model, which depicts physiological properties of the tissues that can be used later for clinical investigations. We developed a LabVIEWbased electrical bioimpedance spectroscopic data interpreter (LEBISDI) for tissue impedance analysis in medical, biomedical and biological applications by studying the equivalent circuit parameters of biological tissues from their Nyquist plots. The performance of LEBISDI was tested, calibrated and evaluated with simulated impedance data as well as with the impedance data collected from a number of high-precision resistor, capacitor and inductor circuit combinations using a standard impedance analyzer with a low amplitude sinusoidal current signal. To study the practical applicability of LEBISDI, we tested biological tissues with an impedance analyzer and the impedance data were interpreted by LEBISDI; their equivalent circuit parameters were also evaluated. Calibration studies show that LEBISDI accurately interpreted the simulated and practical electronic circuit combination data. Furthermore, experimental results show that LEBISDI successfully interpreted the bioimpedance data and estimated the capacitance and resistance of organic tissues. We also observed that LEBISDI efficiently calculated and analyzed variation in the bioimpedance parameters of different tissue compositions. Simulated data and experimental studies demonstrate that LEBISDI can be used to reveal the equivalent circuit parameters from the impedance data obtained from EIS studies. LEBISDI-based studies with a Warburg impedance element could be conducted and reported in future communications. As a future study, the proposed LEBISDI can also be used for electrical impedance-based human tissue characterization, tissue composition analysis, tissue anatomy and health studies and disease diagnosis.

\section{Acknowledgements}

All the authors thank King Abdullah University of Science and Technology (KAUST), Saudi Arabia, and the Indian Institute of Science (IISc), Bangalore, India, for providing research facilities required to complete this work.

\section{References}

1. Martinsen OG, Grimnes S. Bioimpedance and Bioelectricity Basics, second ed., Academic Press, 2008.

2. Ackmann JJ, Complex Bioelectric Impedance Measurement System for the Frequency Range from $5 \mathrm{~Hz}$ to $1 \mathrm{MHz}$, Annals of Biomedical Engineering. 1993; 21: 135-146. http://dx.doi.org/10.1007/BF02367609

3. Cheneler D, Bowen J, Kaklamani G. Transient bioimpedance monitoring of mechanotransduction in artificial tissue during indentation. J Electr Bioimp. 2014; 5(1): 55-73. http://dx.doi.org/10.5617/jeb.869

4. Bera TK, Seo JK, Kwon H and Nagaraju J, A LabVIEW Based Electrical Bio-Impedance Spectroscopic Data Interpreter (LEBISDI) for Studying The Equivalent Circuit Parameters of Biological Tissues, 15th International Conference on Electrical Bio-Impedance (ICEBI) and 14th Conference on Electrical Impedance Tomography (EIT), Germany, 2013, pp 77.

5. Koziol L, Pitre Jr JJ, Bull JL, Dodde RE, Kruger G, Vollmer A, Weitzel WF. The feasibility of using compression bioimpedance measurements to quantify peripheral edema. J Electr Bioimp. 2014; 5(1): 99-109. http://dx.doi.org/10.5617/jeb.929

6. Bauchot AD, Harker FR, Arnold WM. The use of electrical impedance spectroscopy to assess the physiological condition of kiwifruit. Postharvest Biology and Technology. 2000; 18(1): 9-18. http://dx.doi.org/10.1016/S0925-5214(99)00056-3

7. Heymsfield S, Zheng J, Wang M, Gao C, Kim JYH, Choi A, ... \& Kim I. Evaluation of Novel Hand-held Wireless Bioelectrical Impedance Analysis (BIA) Body Composition Devices. The FASEB Journal. 2015;29(1 Supplement):747-2.

8. Azevedo, ERFBM, Alonso, KC, Cliquet Jr, A. Body composition assessment by bioelectrical impedance analysis and body mass index in individuals with chronic spinal cord injury. J Electr Bioimp. 2016; 7(1): 2-5. http://dx.doi.org/10.5617/jeb.2421

9. Bera TK. Bioelectrical impedance methods for noninvasive health monitoring: a review. Journal of Medical Engineering, 2014. http://dx.doi.org/10.1155/2014/381251

10. Kahraman A, Hilsenbeck J, Nyga M, Ertle J, Wree A, Plauth M, Gerken G, Canbay AE. Bioelectrical impedance analysis in clinical practice: implications for hepatitis $\mathrm{C}$ therapy BIA and hepatitis C, Virology Journal. 2010; 7: 191. http://dx.doi.org/10.1186/1743-422X-7-191

11. Orazem ME, Tribollet B. Electrochemical Impedance Spectroscopy. Wiley-Inter Sc., 2008. http://dx.doi.org/10.1002/9780470381588

12. Macdonald RJ. Impedance Spectroscopy. Annals of Biomedical Engineering. 1992; 20: 289-305. http://dx.doi.org/10.1007/BF02368532 
13. Bera TK and Nagaraju J. Electrical Impedance Spectroscopic Study of Broiler Chicken Tissues Suitable for The Development of Practical Phantoms in Multifrequency EIT, J Electr Bioimp. 2011; 1: 48-63. http://dx.doi.org/10.5617/jeb.174

14. Chakraborty S, Das C, Saha R, Das A, Bera NK, Chattopadhyay, D., Karmakar A, Chattopadhyay D, Chattopadhyay S. Investigating the quasi-oscillatory behavior of electrical parameters with the concentration of D-glucose in its aqueous solution at room temperature by employing impedance spectroscopy technique. J Electr Bioimp. 2015; 6(1): 10-17. http://dx.doi.org/10.5617/jeb.2363

15. Sammer M, Laarhoven B, Mejias E, Yntema D, Fuchs EC, Holler G, Brasseur G, Lankmayr, E. Biomass measurement of living Lumbriculus variegatus with impedance spectroscopy. J Electr Bioimp. 2014; 5(1): 92-98. http://dx.doi.org/10.5617/jeb.934

16. Ruiz GA, Zamora ML, Felice CJ. Impedance spectroscopy of yeast cells attached to gold electrodes. J Electr Bioimp. 2014; 5(1): 40-47. http://dx.doi.org/10.5617/jeb.809

17. Birgersson UH, Birgersson E, Ollmar S. Estimating electrical properties and the thickness of skin with electrical impedance spectroscopy: Mathematical analysis and measurements. J Electr Bioimp. 2012; 3(1): 51-60. http://dx.doi.org/10.5617/jeb.400

18. Röthlingshöfer L, Ulbrich M, Hahne S, Leonhardt S. Monitoring change of body fluid during physical exercise using bioimpedance spectroscopy and finite element simulations. J Electr Bioimp. 2011; 2(1): 79-85. http://dx.doi.org/10.5617/jeb.178

19. Repo T, Paine DH, Taylor AG. Electrical impedance spectroscopy in relation to seed viability and moisture content in snap bean (Phaseolus vulgaris L.), Seed Science Research. 2002; 12: 17-29. http://dx.doi.org/10.1079/SSR200194

20. Chowdhury A, Kanti Bera T, Ghoshal D, Chakraborty B. Electrical Impedance Variations in Banana Ripening: An Analytical Study with Electrical Impedance Spectroscopy. Journal of Food Process Engineering. 2016 (in press). http://dx.doi.org/10.1111/jfpe.12387

21. Barsoukov E, Macdonald JR. Impedance Spectroscopy: Theory, Experiment, and Applications. Wiley-Inter Sc.; 2 Ed. 2005.

22. Gomez-Clapers J, Casanella R, Pallas-Areny R. A novel method to obtain proximal plethysmographic information from distal measurements using the impedance plethysmogram. J Electr Bioimp. 2015; 6(1): 44-48. http://dx.doi.org/10.5617/jeb.2575

23. Nyboer J, Kreider MM, Hannapel L. Electrical Impedance Plethysmography - A Physical and Physiologic Approach to Peripheral Vascular Study. Circulation. 1950; 2: 811-821. http://dx.doi.org/10.1161/01.CIR.2.6.811

24. Griffths RW, Philpot ME, Chapman BJ, Munday KA. Impedance cardiography: non-invasive cardiac output measurement after burn injury. Int. J. Tissue React. 1981; 3(1): 47-55.

25. van Eijnatten MA, van Rijssel MJ, Peters RJ, Verdaasdonk RM, Meijer JH. Comparison of cardiac time intervals between echocardiography and impedance cardiography at various heart rates. J Electr Bioimp. 2014; 5(1): 2-8. http://dx.doi.org/10.5617/jeb.690

26. Woltjer HH, Bogaard HJ, de Vries PMJM. The technique of impedance cardiography. European Heart Journal. 1997; 18: 1396-1403.

http://dx.doi.org/10.1093/oxfordjournals.eurheartj.a015464

27. Da Silva JE, De Sá JM, Jossinet J. Classification of breast tissue by electrical impedance spectroscopy. Medical and Biological Engineering and Computing. 2000; 38(1): 26-30. http://dx.doi.org/10.1007/BF02344684

28. Kerner TE, Paulsen KD, Hartov A, Soho SK, Poplack SP. Electrical impedance spectroscopy of the breast: clinical imaging results in 26 subjects. IEEE Transactions on Medical Imaging. 2002; 21(6): 638-645. http://dx.doi.org/10.1109/TMI.2002.800606

29. Laufer S, Ivorra A, Reuter VE, Rubinsky B, Solomon SB. Electrical impedance characterization of normal and cancerous human hepatic tissue. Physiological measurement. 2010; 31(7): 995. http://dx.doi.org/10.1088/0967-3334/31/7/009

30. Halter RJ, Schned A, Heaney J, Hartov A, Schutz S, Paulsen KD. Electrical impedance spectroscopy of benign and malignant prostatic tissues. The Journal of urology. 2008; 179(4): 1580-1586. http://dx.doi.org/10.1016/j.juro.2007.11.043

31. Bonmassar G, Iwaki S, Goldmakher G, Angelone LM, Belliveau JW, Lev MH. On the measurement of electrical impedance spectroscopy (EIS) of the human head. Int. J. Bioelectromagn. 2010; 12(1): 32.

32. Sanchez B, Vandersteen G, Martin I, Castillo D, Torrego A, Riu PJ, Schoukens J, Bragos R. In vivo electrical bioimpedance characterization of human lung tissue during the bronchoscopy procedure. A feasibility study. Med. Eng. Phys. 2013; 35(7): 949-957. http://dx.doi.org/10.1016/j.medengphy.2012.09.004

33. Zheng B, Tublin ME, Klym AH, Gur D. Classification of Thyroid Nodules Using a Resonance-Frequency-Based Electrical Impedance Spectroscopy: A Preliminary Assessment. Thyroid. 2013; 23(7): 854-862. http://dx.doi.org/10.1089/thy.2012.0413

34. Kyle AH, Chan CT, Minchinton AI. Characterization of three-dimensional tissue cultures using electrical impedance spectroscopy. Biophysical journal. 1999; 76(5): 2640-2648. http://dx.doi.org/10.1016/S0006-3495(99)77416-3

35. Yang L. Electrical impedance spectroscopy for detection of bacterial cells in suspensions using interdigitated microelectrodes. Talanta. 2008; 74(5): 1621-1629. http://dx.doi.org/10.1016/j.talanta.2007.10.018

36. K'Owino IO, Sadik OA. Impedance spectroscopy: a powerful tool for rapid biomolecular screening and cell culture monitoring. Electroanalysis. 2005; 17(23): 2101-2113. http://dx.doi.org/10.1002/elan.200503371

37. Schwan HP. Electrical properties of tissues and cell suspensions: mechanisms and models. Proceedings of 16th Annual International Conference of the IEEE Engineering in Medicine and Biology Society. 1994; 1: A70-A71. http://dx.doi.org/10.1109/IEMBS.1994.412155

38. Martinsen $Ø \mathrm{G}$, Grimnes S, Schwan HP, Interface Phenomena and Dielectric Properties of Biological Tissue. Encyclopedia of Surface and Colloid Science. 2002. 2643-2653. 
39. Schwan HP, Electrical Properties of Tissue and Cell Suspensions. In Advances in Biological and Medical Physics, Lawrence, J.H., Tobias, C.A., Eds.; Acad. Press: New York. 1957; V: 147-209.

http://dx.doi.org/10.1016/b978-1-4832-3111-2.50008-0

40. Seo JK, Bera TK, Kwon H, Sadleir R. Effective admittivity of biological tissues as a coefficient of elliptic PDE. Computational and Mathematical Methods in Medicine. 2013; Article ID 353849, 10 pages. http://dx.doi.org/10.1155/2013/353849

41. Miklavcic D, Pavselj N, Hart FX. Electric Properties of Tissues, Wiley Encyclopedia of Biomedical Engineering, John Wiley \& Sons, Inc. 2006. 1-12.

42. Lewis Jr GK, Lewis Sr GK, Olbricht W. Cost-effective broad-band electrical impedance spectroscopy measurement circuit and signal analysis for piezo-materials and ultrasound transducers. Measurement Science and Technology. 2008; 19(10): 105102. http://dx.doi.org/10.1088/0957-0233/19/10/105102

43. Seoane F. Ferreira J, Sanchéz JJ, Bragós R. An analog frontend enables electrical impedance spectroscopy system onchip for biomedical applications. Physiological Measurement. 2008; 29(6): S267. http://dx.doi.org/10.1088/0967-3334/29/6/S23

44. Schröder J, Doerner S, Schneider T, Hauptmann P. Analogue and digital sensor interfaces for impedance spectroscopy. Measurement Science and Technology. 2004; 15(7): 1271. http://dx.doi.org/10.1088/0957-0233/15/7/007

45. Zhao YQ, Demosthenous A, Bayford RH. A CMOS instrumentation amplifier for wideband bioimpedance spectroscopy systems. In Proceedings of the IEEE International Symposium on Circuits and Systems, 2006. ISCAS 2006, 4 pages.

46. Masot R, Alca-iz M, Fuentes A, Schmidt FC, Barat JM, Gil L, Baigts D, Martinez-Ma-es R, Soto, J. Design of a low-cost non-destructive system for punctual measurements of salt levels in food products using impedance spectroscopy. Sensors and Actuators A: Physical. 2010; 158(2): 217-223. http://dx.doi.org/10.1016/j.sna.2010.01.010

47. Chintan M. Bhatt, Nagaraju J. Instrumentation to Estimate the Moisture Content in Bread Using Electrical Impedance Spectroscopy. Sensors \& Transducers Journal. 2008; 97(10): 45-54.

48. Chowdhury A, Nizamudheen VK, Bera TK, Ghoshal D, Chakraborty B. A study on the Impedance variation in Banana during Ripening using AD5933 based Impedance spectrometer with LabVIEW. Proceeding of the IEEE ICSSS-2016, India.

49. Hoja J, Lentka G. Interface circuit for impedance sensors using two specialized single-chip microsystems. Sensors and Actuators A: Physical 2010; 163(1): 191-197. http://dx.doi.org/10.1016/j.sna.2010.08.002

50. Margo C, Katrib J, Nadi M, Rouane A. A four-electrode low frequency impedance spectroscopy measurement system using the AD5933 measurement chip. Physiological Measurement. 2013; 34(4): 391. http://dx.doi.org/10.1088/0967-3334/34/4/391

51. Travis J, Kring J. LabVIEW for Everyone: Graphical Programming Made Easy and Fun, 3 Ed. PHI.
52. Sugihara H, Oka H, Shimono K, Ogawa R, Taketani M.. U.S. Patent No. RE37,977. Washington, DC: U.S. Patent and Trademark Office. 2003.

53. Maxwell JC. A Treatise on Electricity \& Magnetism, vol. 1, London, Oxford Univ. Press. 1892, Chap. 10.

54. Martinsen ØG, Grimnes S, Schwan HP. Biological Tissues: Interfacial and Dielectric Properties, Encyclopedia of Surface and Colloid Science, Volume 2, Ed Somasundaran, P. (2006). CRC press.

55. Franks W, Schenker I, Schmutz P, Hierlemann A. Impedance Characterization and Modeling of Electrodes for Biomedical Applications, IEEE Trans. Biomed. Eng. 2005; 52(7): 1295 1302. http://dx.doi.org/10.1109/TBME.2005.847523

56. Tränkler HR, Kanoun O, Min M, Rist M. Smart sensor systems using impedance spectroscopy. Proc. Estonian Acad. Sci. Eng. 2007; 13(4): 455-478.

57. Lasia A. Electrochemical Impedance Spectroscopy and Its Applications, Modern Aspects of Electrochemistry, B. E. Conway, J. Bockris, and R.E. White, Edts., Kluwer Academic/Plenum, Pub., NY, 1999, Vol. 32, p. 143-248.

58. Schiffbauer J, Park S, Yossifon G. Electrical Impedance Spectroscopy of Microchannel-Nanochannel Interface Devices. Phys. Rev. Letters. 2013; 110: 204504. http://dx.doi.org/10.1103/PhysRevLett.110.204504

59. Song J, Bazant MZ. Effects of Nanoparticle Geometry and Size Distribution on Diffusion Impedance of Battery Electrodes. J. Electrochem. Soc. 2013; 160(1): A15-A24. http://dx.doi.org/10.1149/2.023301jes

60. Qiao G, Hong Y, Ou J, Guan X. Corrosion monitoring of the $\mathrm{RC}$ structures in time domain: Part II. Recognition algorithm based on fractional derivative theory. Measurement. 2015; 67: 84-91. http://dx.doi.org/10.1016/j.measurement.2014.12.048

61. Bisquert J, Garcia-Belmonte G, Fabregat-Santiago F, Roberto Bueno P. Theoretical models for AC impedance of finite diffusion layers exhibiting low frequency dispersion. Journal of Electroanalytical Chemistry. 1999; 475: 152-163. http://dx.doi.org/10.1016/S0022-0728(99)00346-0

62. Wessels JGH (1996) Fungal hydrophobins: proteins that function at an interface. Trends in Plant Science. 1996; 1: 915. http://dx.doi.org/10.1016/S1360-1385(96)80017-3

63. Mouritsen OG, Bloom M. Models of Lipid-Protein Interactions in Membranes. Annual Review of Biophysics and Biomolecular Structure. 1993; 22: 145-171. http://dx.doi.org/10.1146/annurev.bb.22.060193.001045

64. Cole KS. Electric phase angle of cell membranes. J. Gen. Physiol. 1932; 15: 641-649. http://dx.doi.org/10.1085/jgp.15.6.641

65. Kyle UG, Bosaeus I, De Lorenzo AD, Deurenberg P, Elia M, G!omez JM, Heitmann BL, Kent-Smith L, Melchior JC, Pirlich M, Scharfetter H, Schols AMWJ, Pichard C. Bioelectrical impedance analysis - part I: review of principles and methods. Clinical Nutrition. 2004; 23: 1226-1243. http://dx.doi.org/10.1016/j.clnu.2004.06.004

66. Damez JL, Clerjon S, Abouelkaram S, Lepetit J. Dielectric behavior of beef meat in the $1-1500 \mathrm{kHz}$ range: Simulation with the Fricke/Cole-Cole model. Meat Science. 2007; 77: 512-519. http://dx.doi.org/10.1016/j.meatsci.2007.04.028 
67. Garcia-Alonso MC, Saldana L, Alonso C, Barranco V, Munoz-Morris MA, Escudero ML. In situ cell culture monitoring on a Ti-6Al-4V surface by electrochemical techniques. Acta Biomaterialia. 2009; 5: 1374-1384. http://dx.doi.org/10.1016/j.actbio.2008.11.020

68. Pliquett U, Altmann M, Pliquett F, Schoberlein L. Py - a parameter for meat quality. Meat Science. 2003; 65: 142937. http://dx.doi.org/10.1016/S0309-1740(03)00066-4

69. Fernández-Segovia I, Fuentes A, Ali-o M, Masot R, Alca-iz M, Barat JM. Detection of frozen-thawed salmon (Salmo salar) by a rapid low-cost method. Journal of Food Engineering. 2012; 113: 210-216. http://dx.doi.org/10.1016/j.jfoodeng.2012.06.003

70. Valero A, Braschler T, Renaud P. A unified approach to dielectric single cell analysis: Impedance and dielectrophoretic force spectroscopy. Lab on a Chip. 2010;10(17): 2216-2225. http://dx.doi.org/10.1039/c003982a

71. Wilson EB. The structure of protoplasm. Science. 1899; 10: 33-45. http://dx.doi.org/10.1126/science.10.237.33

72. Luby-Phelps K. The physical chemistry of cytoplasm and its influence on cell function: an update. Mol. Biol. Cell. 2013; 24(17): 2593-6. http://dx.doi.org/10.1091/mbc.E12-08-0617.

73. Zhang MIN, Stout DG, Willison JHM. Plant Tissue Impedance and Cold Acclimation: A Re-analysis. Journal of Experimental Botany. 1992; 43(247): 263-266. http://dx.doi.org/10.1093/jxb/43.2.263

74. Zhang MIN, Willison JHM. Electrical Impedance Analysis in Plant Tissues: Impedance Measurement in Leaves. Journal of Experimental Botany 1993; 44(265): 1369-1375. http://dx.doi.org/10.1093/jxb/44.8.1369

75. Buendia R, Gil-Pita R, Seoane F. Cole parameter estimation from the modulus of the electrical bioimpeadance for assessment of body composition. A full spectroscopy approach. J Electr. Bioimp. 2011; 2; 72-78. http://dx.doi.org/10.5617/jeb.197

76. Fricke H, Morse S. The electric resistance and capacity of blood for frequencies between 800 and $4 \frac{1}{2}$ million cycles. J. General Physiol. 1925; 9(2): 153-167. http://dx.doi.org/10.1085/jgp.9.2.153

77. Cole KS, Cole RH. Dispersion and absorption in dielectrics I. Alternating current characteristics. Journal of Chemical Physics. 1941; 9(4); 341-351. http://dx.doi.org/10.1063/1.1750906

78. Kuang W, Nelson SO. Low-Frequency Dielectric Properties of Biological Tissues: A Review with Some New Insights. Transactions of the ASAE. 1998; 41(1); 173. http://dx.doi.org/10.13031/2013.17142

79. Gabriel C, Gabriel S, Courhout E. The dielectric properties of biological tissues: I. Literature survey. Phys Med Biol. 1996; 41(11): 2231-2249. http://dx.doi.org/10.1088/0031-9155/41/11/001

80. Powles JG. Cole-Cole plots as they should be. Journal of Molecular Liquids. 1993; 56: 35-47. http://dx.doi.org/10.1016/0167-7322(93)80017-P

81. Bera TK, Nagaraju J, Lubineau G. Electrical Impedance Spectroscopy (EIS) Based Evaluation of Biological Tissues Phantoms to Study the Multifrequency Electrical Impedance Tomography (Mf-EIT) Systems. Journal of Visualization. 2016; 19(4): 691-713. http://dx.doi.org/10.1007/s12650-016-0351-0
82. Han L, Koide N, Chiba Y, Mitate T. Modeling of an equivalent circuit for dye-sensitized solar cells. Applied Physics Letters. 2004; 84(13): 2433-2435.

http://dx.doi.org/10.1063/1.1690495

83. Kun S, Ristic B, Peura RA, Dunn RM. Real-time extraction of tissue impedance model parameters for electrical impedance spectrometer. Medical \& Biological Engineering \& Computing. 1999; 37(4): 428-432. http://dx.doi.org/10.1007/BF02513325

84. Mellert F, Winkler K, Schneider C, Dudykevych T, Welz A, Osypka M, Gersing E, Preusse CJ. Detection of (Reversible) Myocardial Ischemic Injury by Means of Electrical Bioimpedance, IEEE Trans. Biomed. Eng. 2011; 58(6): 1511-1518. http://dx.doi.org/10.1109/TBME.2010.2054090

85. Casas O, Bragos R, Riu PJ, Rosell J, Tresanchez M, Warren M, Rodriguez-Sinovas A, Carre-o A, Cinca J. In vivo and in situ ischemic tissue characterization using electrical impedance spectroscopy. Annals of the New York Academy of Sciences. 1999; 873(1): 51-58. http://dx.doi.org/10.1111/j.1749-6632.1999.tb09448.x

86. Rigaud B, Hamzaoui L, Frikha MR, Chauveau N, Morucci JP. In vitro tissue characterization and modelling using electrical impedance measurements in the $100 \mathrm{~Hz}-10 \mathrm{MHz}$ frequency range. Physiological Measurement. 1995; 16(3A): A15. http://dx.doi.org/10.1088/0967-3334/16/3A/002

87. Han A, Yang L, Frazier AB. Quantification of the heterogeneity in breast cancer cell lines using whole-cell impedance spectroscopy. Clinical Cancer Research. 2007; 3(1): 139-143. http://dx.doi.org/10.1158/1078-0432.CCR-06-1346

88. Instruction Manual, 7600 Precision LCR Meter, Model B, QuadTech, Inc., 5 Clock Tower Place, 210 East Maynard, Massachusetts, U.S.A. 01754-2530, October, 2002.

89. Chang Z, Pop GAM, Meijer GCM. A Comparison of Twoand Four-Electrode Techniques to Characterize Blood Impedance for the Frequency Range of $100 \mathrm{~Hz}$ to $100 \mathrm{MHz}$, IEEE Trans. Biomed. Eng. 2008; 55(3): 1247-1249. http://dx.doi.org/10.1109/TBME.2008.915725

90. Bera TK, Mohamadou Y, Lee KH, Wi H, Oh TI, Eung EJ, Soleimani M, Seo JK. Electrical Impedance Spectroscopy for Electro-mechanical Characterization of Conductive Fabrics. Sensors. 2014; 14: 9738-9754. http://dx.doi.org/10.3390/s140609738

91. Yúfera A, Rueda A. A Method for Bioimpedance Measure With Four- and Two-Electrode Sensor Systems, 30th Annual International IEEE EMBS Conference Vancouver, British Columbia, Canada, August 20-24, 2008, pp 2318-2321. http://dx.doi.org/10.1109/iembs.2008.4649662

92. Bera TK and Nagaraju J. A MATLAB-Based Boundary Data Simulator for Studying the Resistivity Reconstruction Using Neighbouring Current Pattern. Journal of Medical Engineering. 2013; Article ID 193578; 15 pages. http://dx.doi.org/10.1155/2013/193578

93. Clemente F, Romano M, Bifulco P, Cesarelli M. EIS measurements for characterization of muscular tissue by means of equivalent electrical parameter. Measurement. 2014; 58: 476-482. http://dx.doi.org/10.1016/j.measurement.2014.09.013 
94. Clemente F, Arpaia P, Manna C. Characterization of human skin impedance after electrical treatment for transdermal drug delivery. Measurement. 2013; 46(9): 3494-3501. http://dx.doi.org/10.1016/j.measurement.2013.06.033

95. Mishra V, Bouyad H, Halter RJ. Electrical impedance-based biopsy for prostate cancer detection. In Bioengineering Conference (NEBEC), 2011 IEEE 37th Annual Northeast pp. 1-2, IEEE. http://dx.doi.org/10.1109/nebc.2011.5778712

96. Chao PJ, Huang EY, Cheng KS, Huang YJ. Electrical impedance spectroscopy as electrical biopsy for monitoring radiation sequelae of intestine in rats. BioMed Research International. 2013; Article ID 974614, 7 pages. http://dx.doi.org/10.1155/2013/974614

97. Keshtkar, A., Salehnia, Z., Keshtkar, A., \& Shokouhi, B. Bladder cancer detection using electrical impedance technique (tabriz mark 1). Pathology research international, 2012; Article ID 470101, 5 pages. http://dx.doi.org/10.1155/2012/470101

98. Hope TA, Iles SE. Technology review: the use of electrical impedance scanning in the detection of breast cancer. Breast Cancer Research. 2004; 6(2): 69-74. http://dx.doi.org/10.1186/bcr744

99. Yang L, Bashir R. Electrical/electrochemical impedance for rapid detection of foodborne pathogenic bacteria. Biotechnology Advances. 2008; 26(2): 135-150. http://dx.doi.org/10.1016/j.biotechadv.2007.10.003

100. Yang L, Li Y, Griffis CL, Johnson MG. Interdigitated microelectrode (IME) impedance sensor for the detection of viable Salmonella typhimurium. Biosensors and Bioelectronics. 2004; 19(10): 1139-1147. http://dx.doi.org/10.1016/j.bios.2003.10.009
101. Cai D, Ren L, Zhao H, et al. A molecular-imprint nanosensor for ultrasensitive detection of proteins. Nature Nanotechnology. 2010; 5(8): 597-601. http://dx.doi.org/10.1038/nnano.2010.114

102. Pan S, Rothberg L. Chemical control of electrode functionalization for detection of DNA hybridization by electrochemical impedance spectroscopy. Langmuir. 2005; 21(3): 1022-1027. http://dx.doi.org/10.1021/la048083a

103. Ollmar S, Emtestam L. Electrical impedance applied to non-invasive detection of irritation in skin. Contact Dermatitis. 1992; 27(1): 37-42. http://dx.doi.org/10.1111/j.1600-0536.1992.tb05195.x

104. Longbottom C, Huysmans MCD, Pitts NB, Los P, Bruce PG. Detection of dental decay and its extent using AC impedance spectroscopy. Nature Medicine. 1996; 2(2), 235-237. http://dx.doi.org/10.1038/nm0296-235

105. Tidy JA, Brown BH, Healey TJ, Daayana S, Martin M, Prendiville W, Kitchener HC. Accuracy of detection of high-grade cervical intraepithelial neoplasia using electrical impedance spectroscopy with colposcopy. International Journal of Obstetrics \& Gynaecology. 2013; 120(4): 400-411. http://dx.doi.org/10.1111/1471-0528.12096

106. Keshtkar A, Keshtkar A, Smallwood RH. Electrical impedance spectroscopy and the diagnosis of bladder pathology. Physiological Measurement. 2006; 27(7): 585. http://dx.doi.org/10.1088/0967-3334/27/7/003 